\title{
An InSAR-based survey of volcanic deformation in the central Andes
}

\author{
M. E. Pritchard and M. Simons \\ Seismological Laboratory, Division of Geological and Planetary Sciences, California Institute of Technology, MC 252- \\ 21, Pasadena, California 91125, USA (matt@gps.caltech.edu)
}

[1] We extend an earlier interferometric synthetic aperture radar (InSAR) survey covering about 900 remote volcanos of the central Andes $\left(14^{\circ}-27^{\circ} \mathrm{S}\right)$ between the years 1992 and 2002. Our survey reveals broad $(10 \mathrm{~s}$ of $\mathrm{km})$, roughly axisymmetric deformation at 4 volcanic centers: two stratovolcanoes are inflating (Uturuncu, Bolivia, and Hualca Hualca, Peru); another source of inflation on the border between Chile and Argentina is not obviously associated with a volcanic edifice (here called Lazufre); and a caldera (Cerro Blanco, also called Robledo) in northwest Argentina is subsiding. We explore the range of source depths and volumes allowed by our observations, using spherical, ellipsoidal and crack-like source geometries. We further examine the effects of local topography upon the deformation field and invert for a spherical point-source in both elastic half-space and layered-space crustal models. We use a global search algorithm, with gradient search methods used to further constrain best-fitting models. Inferred source depths are model-dependent, with differences in the assumed source geometry generating a larger range of accepted depths than variations in elastic structure. Source depths relative to sea level are: 8-18 km at Hualca Hualca; $12-25 \mathrm{~km}$ for Uturuncu; $5-13 \mathrm{~km}$ for Lazufre, and 5-10 km at Cerro Blanco. Deformation at all four volcanoes seems to be time-dependent, and only Uturuncu and Cerro Blanco were deforming during the entire time period of observation. Inflation at Hualca Hualca stopped in 1997, perhaps related to a large eruption of nearby Sabancaya volcano in May 1997, although there is no obvious relation between the rate of deformation and the eruptions of Sabancaya. We do not observe any deformation associated with eruptions of Lascar, Chile, at 16 other volcanoes that had recent small eruptions or fumarolic activity, or associated with a short-lived thermal anomaly at Chiliques volcano. We posit a hydrothermal system at Cerro Blanco to explain the rate of subsidence there. For the last decade, we calculate the ratio of the volume of magma intruded to extruded is between $1-10$, and that the combined rate of intrusion and extrusion is within an order of magnitude of the inferred geologic rate.

Components: 7472 words, 17 figures, 3 tables.

Keywords: InSAR volcano; South America.

Index Terms: 1243 Geodesy and Gravity: Space geodetic surveys.

Received 28 July 2003; Revised 18 November 2003; Accepted 21 November 2003; Published 7 February 2004.

Pritchard, M. E., and M. Simons (2004), An InSAR-based survey of volcanic deformation in the central Andes, Geochem. Geophys. Geosyst., 5, Q02002, doi:10.1029/2003GC000610. 


\section{Introduction}

[2] The central Andes $\left(14^{\circ}-28^{\circ} \mathrm{S}\right)$ has a high density of volcanoes (Figure 1), but a sparse human population, such that the activity of most volcanoes is poorly constrained [e.g., de Silva and Francis, 1991]. For example, Simkin and Siebert [1994] list 15 different volcanoes that have erupted in the central Andes during the past century, but some "eruptions" might only be increased fumarolic activity [Simkin and Siebert, 1994; Smithsonian Institution, 1997b]. Furthermore, subtle signs of activity, such as heightened fumarolic activity, are infrequently reported for only a few edifices [e.g., GonzalezFerran, 1995; Smithsonian Institution, 1996b, 1993d].

[3] It is desirable to monitor subtle changes at volcanoes, especially surface deformation, in order to determine whether magma is moving at depth. In some cases, particularly at basaltic volcanoes like Kilauea, Hawaii and Krafla, Iceland, eruptions have been preceded by surface inflation due to magma injection at depth [e.g., Dvorak and Dzurisin, 1997]. This simple relation between deformation and eruption is not the norm, especially at stratovolcanoes [Dvorak and Dzurisin, 1997], common in the central Andes. Therefore a history of deformation and eruption must be established for each volcano. For the hundreds of remote volcanos of the Central Andes, differential repeat-pass satellite interferometric synthetic aperture radar (InSAR) is currently the most viable way to establish the background level of activity.

[4] InSAR measures the change in path length in the satellite line-of-sight (LOS) between observations. Many factors contribute to changes in path length, but with appropriate removal of topographic effects, and if atmospheric and ionospheric effects are small and/or can be isolated, path length changes correspond to deformation of the Earth's surface [e.g., Rosen et al., 2000]. Here, we use ERS-1 and ERS-2 satellite radar images processed to a spatial resolution of $20 \mathrm{~m}$ and image extents greater than $100 \mathrm{~km}$, such that deformation can be monitored at scores of volcanoes in each scene at high spatial resolution. We complement the ERS data with data from the JERS radar satellite.

[5] We use InSAR to extend our systematic observations of deformation at nearly 900 volcanoes in the central Andes [Pritchard and Simons, 2002] between 1992 and 2002 to determine which volcanoes might have magma moving at depth. Here we detail the data used in the survey and its accuracy, including additional data and data reprocessed with digital elevation models (DEM) from the Shuttle Radar Topography Mission (SRTM). We discuss results of modeling the deformation and implications of the lack of deformation we observe during several volcanic eruptions.

\section{Data Used}

[6] The central Andes is generally well-suited for InSAR, although many volcanoes are permanently snow-capped because of their high elevations (dozens exceed $6000 \mathrm{~m}$ ). The lack of rainfall, vegetation, and human cultivation improves the InSAR measurements, which rely upon the radar scattering properties of the Earth's surface remaining coherent between observations. Variations in coherence in the central Andes seem to be related to regional climate (Figure 2). Generally, coherence is lost on the stratovolcano edifice because precipitation is more likely to fall there than on the surrounding lower lying areas, and the steep slopes promote small scale movement. However, InSAR measurements of deformation are possible in almost all regions of low coherence within our study area where we apply spatial averaging (i.e., "looking down" the interferogram) at the expense of spatial resolution.

[7] de Silva and Francis [1991] grouped 1,113 volcanic edifices in the central Andes into different age groups based on their geomorphological characteristics. As the authors note, it is difficult to convert the geomorphological ages into actual ages because the state of preservation of each edifice depends on its composition and local climate. Using geochronological data from a few edifices, several authors have inferred that one of the de Silva and Francis [1991] morphological classes corresponds to volcanoes less than 250,000 years old, another 


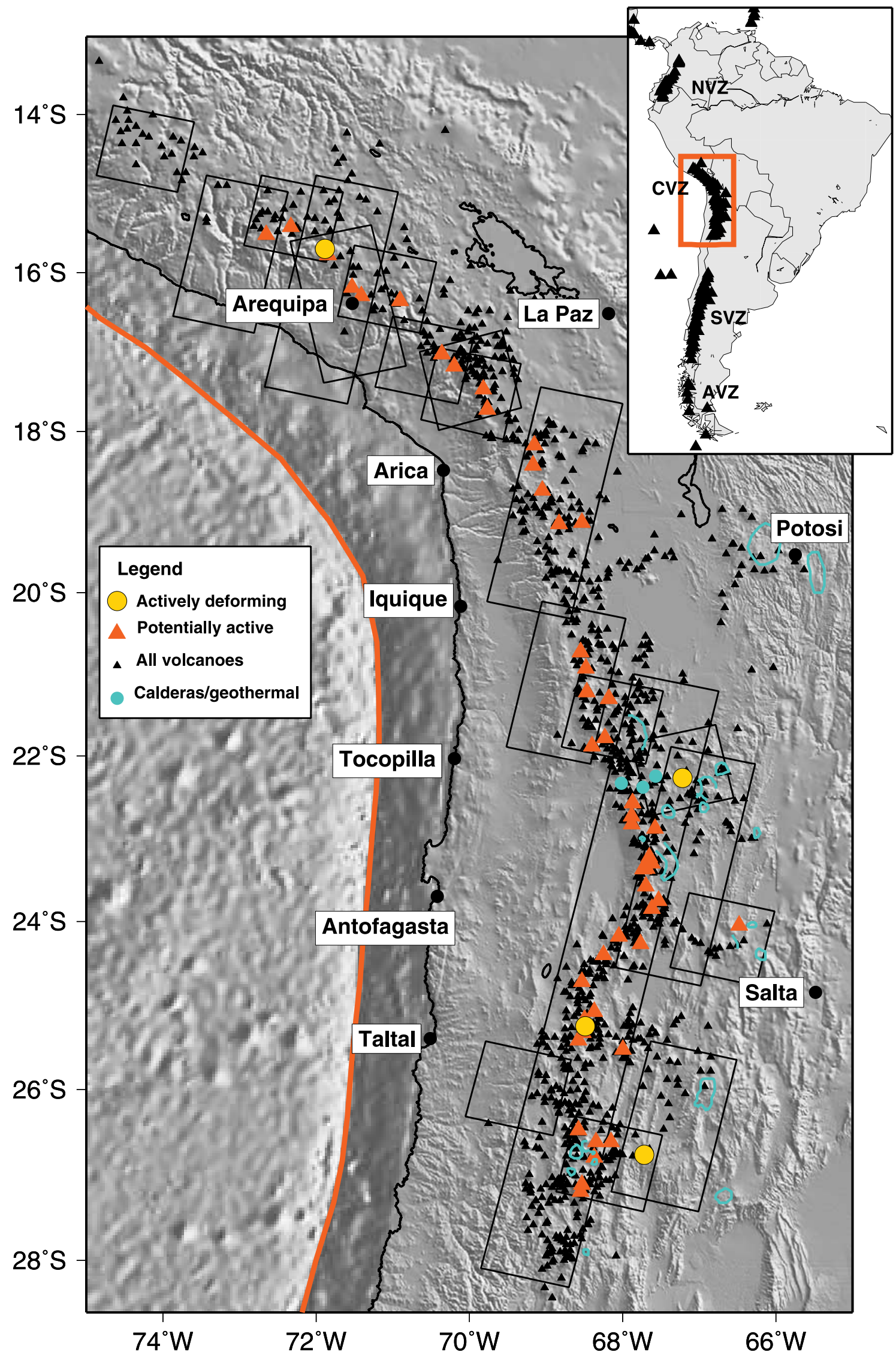


class to those less than 1-2 $\mathrm{Ma}$, and that the entire database includes volcanoes less than 10-20 Ma [Baker and Francis, 1978; de Silva and Francis, 1991; Francis and Hawesworth, 1994]. We selected ERS-1/2 radar data to maximize coverage of the 44 "potentially active" volcanoes determined by de Silva and Francis [1991] to have been the most active since the last glacial maximum (about 10,000 years ago) and augmented the list to 53 including other recently active volcanoes (for a complete list, see Pritchard [2003]).

[8] Table 1 shows a summary of the total number of volcanoes we surveyed of each age and the temporal coverage. We surveyed 945 edifices for a total of about 6200 volcano-years (the sum of the number of years each volcano was surveyed), or 354 volcanoes less than 1-2 Ma for about 2400 volcano-years. We surveyed deformation at 17 known calderas [de Silva and Francis, 1991; Riller et al., 2001] and three geothermal fields. We sought data for each edifice during the entire period when radar data was available (1992-2002), but this was not possible due to constraints on data availability. In total, we used about 160 scenes of radar data to create more than 80 interferograms, most of which can be viewed as part of the electronic Appendix of Pritchard [2003]. The data used in modeling the deformation is shown in Table 2.

[9] We process the radar data using the Caltech/JPL InSAR package, ROI_PAC. We use satellite orbital information from the Delft Institute for Earth-Oriented Space Research [Scharroo et al., 1998]. We remove topographic effects with both the 2-pass approach where a preexisting DEM is used, and the 4-pass approach using ERS-1/2 tandem data, i.e., separated in time by one day. We process every interferogram using the 2-pass approach, but also use the 4-pass approach when tandem data are available, to check for atmospheric effects and phase unwrapping errors in the tandem data. We discuss these errors in the "Measurement Accuracy" section below. Technical problems encountered during processing are documented in Pritchard [2003].

\section{Modeling Strategy}

[10] Although deformation data can provide useful constraints on source processes, the data are subject to multiple interpretations. Owing to the unknown nature of the source of deformation (i.e., source shape, spatial extent, depth, etc.), and the spatial variation of the elastic properties of the crust, surface observations provide nonunique constraints on processes occurring at depth. It is most often assumed that the source is a spherically symmetric point source and that the crust is an isotropic, homogeneous half-space (the so-called "Mogi" model), although nonspherical sources, and finite sources have also been explored [Dieterich and Decker, 1975; Davis, 1986; Yang et al., 1988; Fialko et al., 2001a]. The sources of deformation are usually assumed to be caused by changes in volume (due to the injection or withdrawal of magma or hydrothermal fluids, and/or expansion and contraction caused by temperature or phase changes), such that there is no component of shear. Nonspherical sources that are prolate ("pluton-like"), or oblate ("sill-like") ellipsoids might be more realistic than a spherical source [e.g., Davis, 1986]. Yet, the practical limitations that observations are made at the Earth's surface, and are often limited to a single component of deformation, mean that it is difficult to differentiate between the types of sources [Dieterich and Decker, 1975; Fialko et al., 2001a]. For example, while it is possible to use multiple InSAR observations from many different viewing geometries to

Figure 1. Shaded relief map of the Central Andes including the 1,113 potential volcanic edifices compiled by de Silva and Francis [1991] (black triangles), and "potentially active" volcanoes of de Silva and Francis [1991] plus other volcanoes found to be active since their study (red triangles). Yellow circles show actively deforming volcanoes found in this study. Light blue circles show location of geothermal fields. The light blue lines outline the large silicic calderas listed by de Silva and Francis [1991] and Riller et al. [2001]. Reference map in upper right shows study area (red box) in the Central Volcanic Zone (CVZ) relative to the other South American volcanic belts: Northern Volcanic Zone (NVZ), Southern Volcanic Zone (SVZ) and the Austral Volcanic Zone (AVZ). Major cities are indicated. The red line in the ocean is the location of the subduction zone trench. Black square outlines show the location of radar data used in this study. 


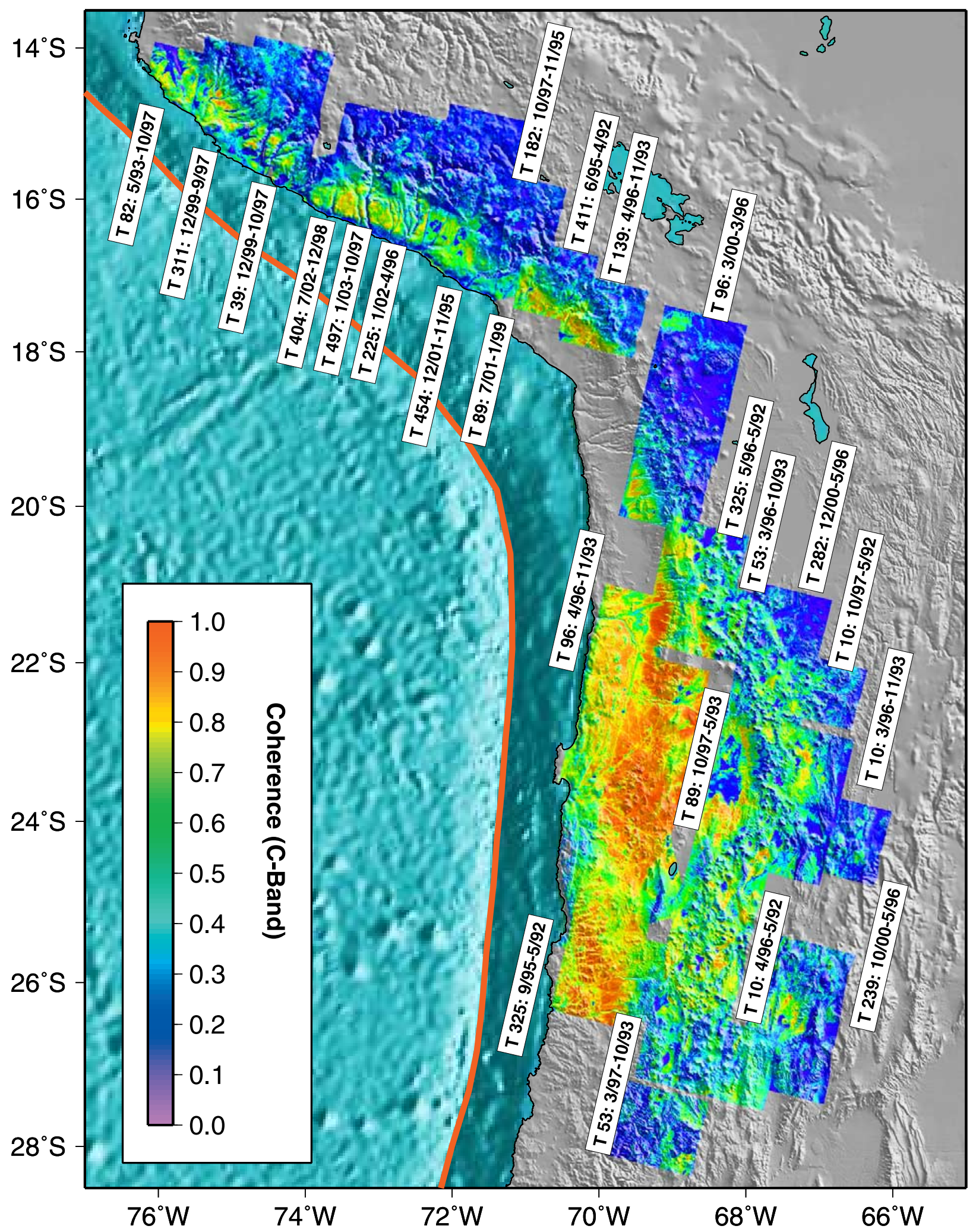


Table 1. Volcanoes Surveyed in the Central Andes ${ }^{\mathrm{a}}$

\begin{tabular}{clcccc}
\hline $\begin{array}{c}\text { Morphological } \\
\text { Class }\end{array}$ & $\begin{array}{c}\text { Estimated } \\
\text { Age, yrs }\end{array}$ & $\begin{array}{c}\text { Number } \\
\text { Edifices }^{\mathrm{b}}\end{array}$ & $\begin{array}{c}\text { Number } \\
\text { Surveyed, \% }\end{array}$ & $\begin{array}{c}\text { Mean } \\
\text { yrs/volc }\end{array}$ & $\begin{array}{c}\text { Cumulative } \\
\text { Volcano-Years }\end{array}$ \\
\hline $1-5$ & $<10-20 \mathrm{Ma}^{\mathrm{c}, \mathrm{d}}$ & 1,113 & $945(85 \%)$ & 6.6 & 6,239 \\
$1-2$ & $<1-2 \mathrm{Ma}^{\mathrm{c}, \mathrm{d}, \mathrm{e}}$ & 390 & $354(91 \%)$ & 6.8 & 2,393 \\
1 & $<10,000^{\mathrm{f}}$ & 112 & $108(96 \%)$ & 7.1 & 762 \\
"Potentially active" & $<10,000^{\mathrm{f}}$ & $53^{\mathrm{g}}$ & $53(100 \%)$ & 7.5 & 399 \\
\hline
\end{tabular}

\footnotetext{
${ }^{\mathrm{a}}$ The number of volcanoes surveyed for deformation and the timespan of data coverage for different geomorphological classes of volcanoes. Relating geomorphological features to age is notoriously difficult (see text) and is at best accurate within a factor of two. We calculate the amount of time each volcano is surveyed and then sum up the total time in each morphological class (cumulative volcano years). We divide the cumulative sum by the number of volcanoes of that age to get the mean number of years each volcano has been surveyed. For some volcanoes, the effective timespan is increased by overlapping data from the same orbital track that can be stacked together, but this effect is not accounted for here. Some volcanoes are imaged in multiple orbital tracks.

${ }^{\mathrm{b}}$ de Silva and Francis [1991].

${ }^{\mathrm{c}}$ Francis and Hawesworth [1994].

$\mathrm{d}$ Wörner et al. [2000].

e Baker and Francis [1978].

${ }^{\mathrm{f}}$ These volcanoes lack glacial features, so have presumably been active in the last 10,000 years, although the volcanoes are probably older than this and likely at least 250,000 years old [Francis and Hawesworth, 1994].

${ }^{\mathrm{g}}$ The original list of potentially active volcanoes [de Silva and Francis, 1991] has been augmented by this study (see text).
}

construct a complete three-dimensional (3-D) deformation field [Fialko et al., 2001b], in the central Andes, data are frequently only available from a single satellite line-of-sight (LOS) direction. In fact, only three interferograms were made from ascending data in our analysis.

[11] When only one component of InSAR data are available, the data can be fit equally well by multiple types of sources. For a given deformation source, the different source geometries have different inferred depths [Fialko et al., 2001b]. There is also a trade-off between source depth and source strength (or the volume of magma injection/withdrawal), such that to get roughly equivalent surface deformation a relatively deeper source requires a larger source strength. To further complicate the interpretation, if the elastic medium is not a halfspace, but is a more realistic layered and heterogeneous structure, the inferred source depth and geometry can be effected [e.g., Du et al., 1997; Cattin et al., 1999]. Inferred source depths can also be impacted by including the effects of topography instead of simply assuming a half-space [e.g., Williams and Wadge, 1998]. Considering all of the variables, a primary purpose of this paper is to explore a range of models (e.g., spherical, prolate ellipsoids, and penny-shaped cracks) that fit the data, with different elastic structures and source geometries, both including topography or neglecting it.

\subsection{Inversion Method}

[12] Given an elastic structure (half-space or layered-space) and a deformation source type (spherical, axisymmetric prolate or oblate spheroids), we minimize the misfit between data and model in a least squares sense. For problems that are nonlinear with noisy data, there may be many local minima in the misfit surface [e.g., Cervelli et al., 2001]. An inversion method must reveal the range of models that fit the data. We use the Neighborhood Algorithm (NA) [Sambridge, 1998, 1999a, 1999b,

Figure 2. Interferometric coherence for ERS C band radar (wavelength $=5.6 \mathrm{~cm}$ ) for the area where we have studied tectonic and volcanic deformation in west-central South America. The data in this figure is from this study and our other studies of earthquake deformation [Pritchard, 2003]. Interferometric coherence is wavelength dependent, such that longer wavelengths (e.g., the L-band at $24 \mathrm{~cm}$ wavelength) retain their coherence over longer time periods than the C-band data used here [e.g., Rosen et al., 1996]. We observe high interferometric coherence near the arid coast, but low coherence in mountainous areas. There also appears to be a north-south trend with higher coherence south of $21^{\circ} \mathrm{S}$, where the zone of high coherence along the coast is wider than in southern Peru. The coastinland and north-south variations in coherence are presumably related to regional climate variations, with more precipitation falling in the north (related to the "Bolivian winter" meteorological effect) and in mountainous areas [e.g., de Silva and Francis, 1991; Montgomery et al., 2001]. 
Table 2. InSAR Data Used at Actively Deforming Volcanoes ${ }^{\mathrm{a}}$

\begin{tabular}{|c|c|c|c|c|c|}
\hline Volcano & Track & Frame(s) & Master Image & Slave Image & $\mathrm{B}_{\perp}, \mathrm{m}$ \\
\hline \multirow[t]{21}{*}{ Hualca Hualca } & 454 & 3925 & 25 Apr. 1996 & 2 Jun. 1992 & 60 \\
\hline & 454 & $3915-3933$ & 7 Dec. 1995 & 7 Jul. 1992 & 170 \\
\hline & 454 & 3925 & 31 Jan. 1997 & 31 Aug. 1993 & 70 \\
\hline & 454 & $3915-3933$ & 18 Oct. 1996 & 7 Jul. 1992 & 80 \\
\hline & 454 & 3925 & 24 Aug. 1995 & 31 Aug. 1993 & 50 \\
\hline & 454 & $3915-3933$ & 2 Oct. 1997 & 18 Oct. 1996 & 140 \\
\hline & 454 & 3925 & 31 Jan. 1997 & 24 Aug. 1995 & 120 \\
\hline & 454 & $3915-3933$ & 2 Oct. 1997 & 7 Jul. 1992 & 130 \\
\hline & 454 & $3915-3933$ & 13 Sep. 1996 & 2 Oct. 1997 & 160 \\
\hline & 454 & 3925 & 31 Jan. 1997 & 13 Sep. 1996 & 30 \\
\hline & 454 & $3915-3933$ & 18 Oct. 1996 & 7 Dec. 1995 & 260 \\
\hline & 454 & 3925 & 13 Sep. 1996 & 31 Aug. 1993 & 205 \\
\hline & 454 & $3915-3933$ & 2 Nov. 1995 & 7 Jul. 1992 & 270 \\
\hline & 454 & $3915-3933$ & 2 Nov. 1995 & 21 Dec. 2001 & 110 \\
\hline & 454 & 3925 & 24 Aug. 1995 & 13 Sep. 1996 & 260 \\
\hline & 89 & 6867 & 10 Jan. 1999 & 9 Jul. 2001 & 170 \\
\hline & p424 & 327 & 22 Oct. 1996 & 12 Apr. 1994 & $600^{\mathrm{b}}$ \\
\hline & p424 & 327 & 5 Dec. 1996 & 12 Apr. 1994 & $150^{\mathrm{b}}$ \\
\hline & 454 & $3915-3933$ & 7 Dec. 1995 & 21 Dec. 2001 & 220 \\
\hline & 89 & 6849 & 11 Jan. 1999 & 15 Apr. 2002 & $120^{\mathrm{c}}$ \\
\hline & 454 & 3915 & 25 Apr. 1996 & 5 Apr. 2002 & $290^{\mathrm{c}}$ \\
\hline \multirow[t]{12}{*}{ Uturuncu } & 3 & 6741 & 6 Oct. 1997 & 4 Apr. 2000 & 80 \\
\hline & 282 & 4059 & 18 May 1996 & 24 Dec. 2000 & 30 \\
\hline & 282 & 4059 & 13 Apr. 1996 & 6 Aug. 2000 & 60 \\
\hline & 282 & 4059 & 12 Aug. 1995 & 24 Dec. 2000 & 120 \\
\hline & 282 & 4059 & 12 Aug. 1995 & 19 May 1996 & 20 \\
\hline & 10 & 4059 & 2 May 1992 & 7 Oct. 1997 & 100 \\
\hline & 10 & 4059 & 7 Oct. 1997 & 21 Dec. 1999 & 150 \\
\hline & 10 & 4059 & 2 May 1992 & 30 Apr. 1996 & 270 \\
\hline & 10 & 4059 & 2 Oct. 1995 & 21 Dec. 1999 & 20 \\
\hline & 10 & 4059 & 2 Oct. 1995 & 7 Oct. 1997 & 130 \\
\hline & 10 & 4059 & 2 May 1992 & 21 Dec. 1999 & 250 \\
\hline & 10 & 4059 & 2 May 1992 & 2 Oct. 1995 & 220 \\
\hline \multirow[t]{8}{*}{ Lazufre } & 282 & 4113 & 8 Jul. 1995 & 26 Oct. 1997 & 65 \\
\hline & 282 & 4113 & 13 Apr. 1996 & 8 Aug. 2000 & 70 \\
\hline & 282 & 4113 & 14 Apr. 1996 & 8 Aug. 2000 & 150 \\
\hline & 282 & 4113 & 12 Aug. 1995 & 24 Dec. 2000 & 180 \\
\hline & 282 & 4113 & 18 May 1996 & 24 Dec. 2000 & 80 \\
\hline & 282 & 4113 & 19 May 1996 & 24 Dec. 2000 & 190 \\
\hline & 282 & 4113 & 26 Oct. 1997 & 7 Jul. 2002 & $120^{\mathrm{c}}$ \\
\hline & 282 & 4113 & 12 Aug. 1995 & 19 May 1996 & 15 \\
\hline \multirow[t]{7}{*}{ Cerro Blanco } & 10 & 4149 & 30 Apr. 1996 & 2 May 1992 & 270 \\
\hline & 10 & 4149 & 7 Oct. 1997 & 2 May 1992 & 170 \\
\hline & 239 & 4149 & 12 Oct. 2000 & 16 May 1996 & 5 \\
\hline & 10 & 4149 & 2 Oct. 1995 & 2 May 1992 & 300 \\
\hline & 10 & 4149 & 7 Oct. 1997 & 2 Oct. 1995 & 130 \\
\hline & 10 & 4149 & 6 Oct. 1997 & 2 Oct. 1995 & 210 \\
\hline & 10 & 4149 & 29 Apr. 1996 & 2 May 1992 & 190 \\
\hline
\end{tabular}

\footnotetext{
${ }^{\mathrm{a}}$ Interferograms made at the four actively deforming centers and used in the inversions for source parameters.

${ }^{\mathrm{b}}$ The two JERS interferograms were stacked together to increase the signal-to-noise ratio (see text).

${ }^{\mathrm{c}}$ These interferograms were attempted, because the ERS catalog indicated that they were on the correct Doppler ambiguity. However, the interferograms could not be made, perhaps indicating a problem with the ERS Doppler catalog.
}

2001], which samples the entire model parameter space, but focuses on regions of low misfit. The NA method seems able to find many local minima with only two user supplied tuning parameters, and has been used in several geophysical applications [e.g., Sambridge and Kennett, 2001; Lohman et al., 2002]. We use the NA to generate scatterplots that show misfit as a function of the various model 

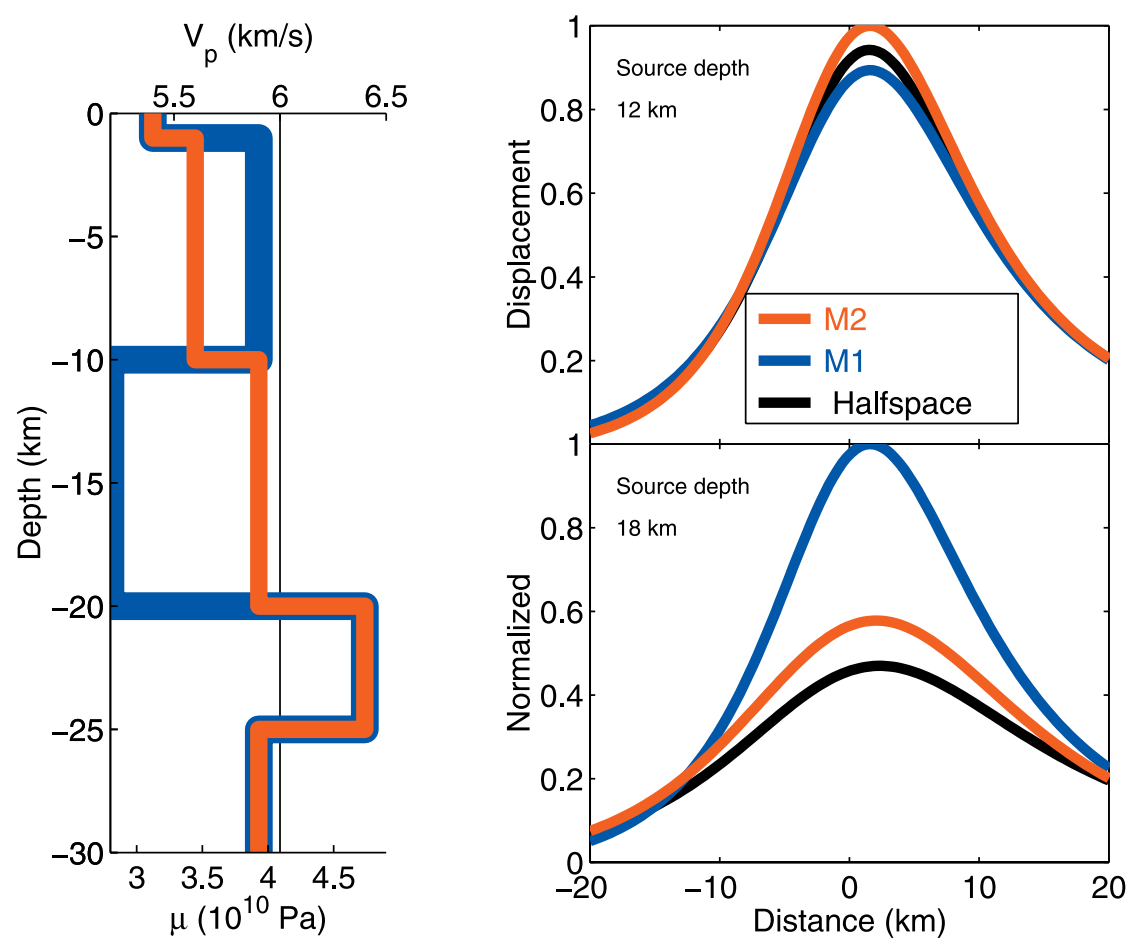

Figure 3. The effects of different elastic structures on surface deformation. (left) Velocity as a function of depth used for the half-space and two layered-space models considered. In the EDK program, we specify the P wave velocity, $V_{p}$, the $\mathrm{S}$ wave velocity, $V_{s}$, and the density, which are used to calculate the rigidity ( $\mu$ in figure). We take the $V_{p}$ for our models from different locations in the western cordillera and Altiplano from the seismic profile of Wigger et al. [1994] at $21^{\circ} \mathrm{S}$. We use the density values (constrained by gravity) along the same profile from Schmitz et al. [1997]. We assume that the elastic structure is Poissonian, although there are indications that this assumption is wrong by about 4\% in some locations [Myers et al., 1998; Graeber and Asch, 1999]. (top right) Surface deformation (normalized by the maximum displacement of the three models) in the radar LOS for the three elastic media with a constant source at $12 \mathrm{~km}$. (bottom right) Surface deformation in the radar LOS for the three elastic media with a constant source at $18 \mathrm{~km}$. The presence of LVZ's affects the relative amplitude of deformation. In the top right panel, the source is located at $12 \mathrm{~km}$, and the weak upper layers of the M2 structure allow deformation to exceed that from the half-space, while the location of the source within the upper LVZ of M1, reduces the deformation compared to that of the half-space. When the source is moved deeper, to $18 \mathrm{~km}$, deformation from model M2 still exceeds deformation in the half-space. In addition, the integrated effect of the LVZ in model M1 allows deformation to surpass that of the half-space.

parameters to determine whether an individual parameter is well constrained, and determine the correlation between pairs of variables. In tests with synthetic noisy data, we were able to solve for the input variables with the NA algorithm when there were few model parameters (e.g., the spherical point source). However, when the number of model parameters is increased, (e.g., the prolate ellipsoid) there were so many nearly equal minima in misfit space that the algorithm did not always recover the input parameters. Therefore in order to more fully explore parameter space, we have also done inversions using conjugate gradient methods (Gauss-Newton and
Levenberg-Marquardt, as implemented in the MATLAB Optimization Toolbox). These methods are more susceptible to local minima, so we have used a variety of initial conditions (sometimes motivated by results from the NA algorithm) to better understand the range of acceptable model parameters. For example, because we are interested in the range of source depths that can explain the deformation, we start the prolate ellipsoid model at a variety of source dips and depths and the penny-shape crack with many different depths and radii. In the results discussed below, we use both complementary methods to constrain the range of source depths. 
[13] We choose to invert for as few parameters as possible. Before we begin the inversion, we mask out the region of volcanic deformation, then estimate the best-fitting two-dimensional (2-D) linear ramp with three variables (or in rare cases, a quadratic ramp with six components) that removes the long-wavelength signals caused by orbital errors, atmospheric effects, or broad deformation unrelated to the local volcano. Quadratic changes in the baseline become important when many image frames (as many as seven in this study) are concatenated together [Pritchard et al., 2002]. We allow the inversion to solve for an absolute (constant) offset between the InSAR measurements and the model prediction, because InSAR measures only relative, not absolute displacement. The absolute offset term is small, usually less than $1 \mathrm{~cm}$.

\subsection{Magma Reservoir Shape and Location}

[14] For all sources, we invert for the $x, y$, and $z$ location of the source, and the absolute offset. For the spherically symmetric source we also estimate the volume injected/withdrawn. For the prolate ellipsoid [Yang et al., 1988], we fix the semimajor axis to be $1 \mathrm{~km}$ (which effectively makes the ellipsoid a point source), because the effects of the finite size of the source are only important in extreme and probably unrealistic conditions involving a large source that extends near the surface. Furthermore, our tests with synthetic and real data indicate that the InSAR observations are rather insensitive to the finite size for our deformation sources (e.g., there is a trade-off between source radius, source depth and source volume). In addition to the parameters mentioned above, for the prolate ellipsoid we also solve for the pressure change, ratio between the semimajor and semiminor axes, and the strike and dip of the ellipsoid. For the penny-shaped crack [Fialko et al., 2001a], we solve for the radius of the crack and the pressure change. For each volcano, we jointly invert as much data from different time periods or satellite tracks, each of which has a slightly different viewing geometry, as possible. The unwrapped data used in the inversion has been spatially averaged to yield a pixel resolution of about $350 \mathrm{~m}$, suffi- cient to resolve the smooth deformation pattern from deep magma sources. The data are resampled based on the local curvature of the deformation field [Simons et al., 2002] such that typically several thousand points are used in any inversion (a few percent of the original number of pixels). In the joint inversions, we solve for a single location and source geometry for all interferograms, but allow the source strength to be solved independently for each time span.

[15] For the spherical point source, we generate surface displacements in a half-space and layered-space using propagator matrices with frequency-wave number (F-K) summation via the Elementary Displacement Kernel (EDK) software (Simons and Rivera, in preparation, 2003). For a given elastic structure, we precalculate displacement kernels for "elementary" point sources. Surface deformation from an arbitrary point source can be quickly calculated by a linear combination of the "elementary" cases. This method precalculates the Green's functions for each elementary case, allowing for fast calculation of displacement via a look-up table.

\subsection{Elastic Structure}

[16] The crust of the central Andes is both laterally and vertically variable, and although there have been many recent investigations of velocity structure [e.g., Wigger et al., 1994; Yuan et al., 2000], the exact structure in the vicinity of each deforming edifice is poorly constrained. A particular complication is the variable existence, depth, and magnitude of low seismic velocity zones throughout the region that have been used to infer zones of partial melting [e.g., Schmitz et al., 1997; Chmielowski et al., 1999; Yuan et al., 2000]. Considering the uncertainties, we have chosen to test the effects on the inferred source depth from two different one-dimensional (1-D) layered elastic models for the spherical point source, in addition to the elastic half-space (Figure 3). Although the velocity models we use are motivated by data, we do not believe the details, since they are sensitive to the chosen parameterization. The models were chosen to represent some end-member velocity structures. 
[17] We explore the sensitivity of surface deformation to two elastic structures (Figure 3). Model M1 has two low-velocity zones (LVZ), between 10$20 \mathrm{~km}$ and below $25 \mathrm{~km}$, and model M2 only has the LVZ below $25 \mathrm{~km}$. The LVZ below about $25 \mathrm{~km}$ is a pervasive feature in the central Andes, although its depth is variable [Yuan et al., 2000], while the shallower LVZ is more spatially variable [Wigger et al., 1994]. The velocity and density are extremely variable in the uppermost layer, although our tests indicate that for the source depths in the regions considered, the inferred source depth is not very sensitive to reasonable variations in those parameters. The relative amplitude of surface deformation from the half-space and layered models is sensitive to the depth of a given source. Thus the presence and depth extent of the LVZs can influence deformation. However, we show that for our sources, the variable material properties seem to have only a secondary impact on inferred source depth compared to different source geometry.

\section{Results}

[18] Of the 900 hundred volcanoes surveyed, we found broad (10s of $\mathrm{km})$, roughly axisymmetric, centimeter-scale deformation at four centers with no previously documented deformation [Pritchard and Simons, 2002]. Two stratovolcanoes are inflating (Uturuncu, Bolivia, and Hualca Hualca, Peru), and another source of inflation is seen between Lastarria and Cordon del Azufre on the border between Chile and Argentina, that is not associated with a volcanic edifice (which will hereafter be called "Lazufre"). A caldera (Cerro Blanco, also called Robledo) in northwest Argentina is subsiding. Here we document the quality of the data and the criteria used to differentiate deformation from noise.

[19] None of the deforming sources were listed as active volcanoes, although Hualca Hualca, Peru, and Lazufre could be related to other, well known volcanoes (see below). While the four actively deforming volcanoes have had no known eruptions, Lascar, Chile, has erupted several times, but we do not observe deformation between 5/1992$12 / 2001$. We found no measurable deformation at other volcanoes that had documented small eruptions or fumarolic activity during the period when radar observations were made: Ubinas (Peru) [Smithsonian Institution, 1996a], Guallatiri [Smithsonian Institution, 1996b], Irruputuncu [Smithsonian Institution, 1997b; Zebker et al., 2000], Aracar [Smithsonian Institution, 1993a], and Ojos del Salado [Smithsonian Institution, 1993d] (all in Chile). The eruptions at Sabancaya, Peru, [Smithsonian Institution, 1994a, 1995, 1997a, 1998a, 1998b, 1998c, 2000a] will be discussed in detail below. Further, we did not observe deformation at other volcanoes with known fumarolic activity, although no activity was documented during the period of radar observations (Misti, Tutupaca, both in Peru; Tacora, Isluga, Olca and Paruma, Aucanquilcha, Ollague, San Pedro, Putana, Lastarria, all in Chile) [J. Clavero and J. Naranjo, personal communication, 2002; de Silva and Francis, 1991].

[20] We observe several nonvolcanic sources of deformation, including heterogeneous swelling and subsidence at several salt flats (salars), a possible shallow earthquake in Chile, possible hydrological activity in volcanic areas associated with a large subduction zone earthquake, and some sources of unknown origin in southern Peru. A more detailed discussion of each individual volcanic and nonvolcanic source of deformation is available in Pritchard [2003].

\subsection{Measurement Accuracy}

[21] We find that a small fraction of all volcanoes in the central Andes are presently deforming. However, it is possible that other volcanoes are deforming at rates that are below our detection threshold. Even where coherence is high and the phase can be unwrapped, sensitivity is not the same in all locations because of variations in atmospheric noise, and the amount of redundant data available that can be used for averaging (also known as stacking).

[22] The accuracy of InSAR measurements is not yet well-quantified (but see Hanssen [2001]; Jonsson [2002]; Emardson et al. [2003]). Direct comparison of InSAR with GPS observations (on the scale of an individual pixel) for several large 
earthquakes indicates cm-scale accuracy [e.g., Massonnet et al., 1993; Zebker et al., 1994; Fialko, $2001 \mathrm{c}]$, and in ideal circumstances, sub-cm accuracy is possible [Zebker et al., 1997]. Within our study area, we estimate accuracies of about $1-2 \mathrm{~cm}$ over length scales at least $10 \mathrm{~km}$ in size, although differentiating such a signal from atmospheric noise can be difficult.

[23] We base our estimate of accuracy on: (1) the ability to detect a "known" signal at Hualca Hualca and Uturuncu within a short period interferogram. We claim that the signal is "known" because deformation was observed in longer period interferograms spanning the same time interval, and we assume the rate of deformation is nearly constant over the given time period, a reasonable assumption, see below; (2) Comparison of interferograms containing deformation that cover essentially the same time period, including interferograms at Cerro Blanco that differ by only 1 day (made using a tandem pair); and (3) The size of the residual from our model fits is usually less than a centimeter. There is a correlation between accuracy and latitude, because atmospheric effects are larger and coherence is lower north of about $21^{\circ} \mathrm{S}$ (most likely related to climatic variations, as previously discussed).

[24] Our longest interferograms span about five years (limited by data availability and maintaining interferometric coherence). Thus with a sensitivity of 1-2 cm per interferogram, we estimate a detection threshold of about $4 \mathrm{~mm} / \mathrm{yr}$, assuming the deformation rate is constant. With stacking, we have achieved effectively ten year interferograms in a few locations (e.g., tracks 454, 325, and 96), but since the atmospheric noise is higher in these locations in the northern part of our study area, we still estimate that a signal above $4 \mathrm{~mm} / \mathrm{yr}$ is required.

[25] We use the following criteria for differentiating between atmospheric effects and surface deformation: (1) Is the signal observed in independent interferograms, and does it have the same sign? Atmospheric effects can be isolated using pair-wise logic, i.e., forming several interferograms with each individual scene to determine which one contains the anomalous signal [Massonnet and Feigl, 1998]. Because of the lack of data in the central Andes, pair-wise logic is of limited use. If two independent interferograms over an identical time period show signals with different signs, it is clearly atmospheric. Because volcanoes have been observed to move up and down [e.g., Lowry et $a l ., 2001]$, it is harder to rule out sign changes in temporally nonoverlapping or only partially overlapping interferograms. (2) Do nearby edifices show the same pattern? An atmospheric origin is the simplest explanation for many adjacent edifices with similar topography, the same magnitude signal, and/or having a signal that changes sign contemporaneously. (3) Is the deformation pattern confined strictly to the edifice itself, or does it extend far beyond it? If the signal is strongly correlated with topography, this suggests an atmospheric origin. A source beneath a volcanic edifice might cause deformation that is correlated with topography, but unless the source is very shallow (i.e., $1-2 \mathrm{~km}$ below the surface, or within the edifice itself), the deformation pattern will be much broader than the volcano. Thus our selection criteria limits us to large-scale deformation from deep sources $(>1 \mathrm{~km}$ deep, depending on the size of the edifice). A signal not correlated with topography could be deformation, or it could be atmospheric turbulence, so independent interferograms are necessary, see criterion (1). (4) What is the magnitude of the signal? Hanssen [2001] predicts that the maximum signal due to atmospheric stratification is of order $4 \mathrm{~cm}$ (about 1.5 fringes for ERS). Under extreme conditions, the atmospheric signal could be larger [Beauducel et al., 2000; Puglisi and Coltelli, 2001], but we would expect to see the same effect at all nearby edifices with similar topography, criterion (2). The deformation signal at all the volcanoes we infer to be actively deforming is more than $5 \mathrm{~cm}$ in the LOS direction.

\subsection{Deforming Volcanoes}

\subsubsection{Uturuncu}

[26] This stratovolcano lying in southwestern Bolivia, was observed to have weak active fumaroles [Fernández et al., 1973] near the summit (temper- 
atures $<80^{\circ} \mathrm{C}$ ), and shallow seismicity (about 15 events/hour at 3-4 $\mathrm{km}$ depth) during a visit in April 2003 [Smithsonian Institution, 2003]. Kussmaul et al. [1977] claimed that Uturuncu has lava flows overlying glacial moraines, but such features were not seen in satellite images [de Silva and Francis, 1991], or during a field survey in April 2003 [Smithsonian Institution, 2003]. We have made a total of 12 interferograms for Uturuncu covering 2 May 1992 to 24 December 2000, 11 interferograms from two tracks of descending data and one interferogram from one track of ascending data. Uturuncu is deforming during the entire time interval at a maximum rate between $1-2 \mathrm{~cm} / \mathrm{yr}$ in the LOS direction (assuming that the deformation rate is constant during the time period of the interferogram).

[27] Figure 4 shows the data, model, residual and profiles for three interferograms from three different tracks of satellite data. A complete list of the interferograms used in the inversions for this and the other volcanoes is shown in Table 2. The observed and predicted interferograms are shown as rates, while the residual and profiles are shown as absolute displacements. The data shown are cropped from the full interferogram, but we have done other inversions using nearly the complete interferograms, and the results in terms of source depths, location and strengths are similar, although the model fit to the data is not as good.

\subsubsection{Effects of Elastic Structure}

[28] Using the NA algorithm, we estimate misfit as a function of the different model parameters for three assumed elastic models: a half-space and two depth-dependent models (M1 and M2, Figure 5). The inversions shown used five interferograms from the three different satellite tracks. Although the misfit function is usually peaked near the best estimate, because of the data noise and nonuniqueness of the problem, we instead choose to use the width of the misfit function to specify a range of values for each parameter. The half-space model provides the best fit, perhaps because of our crude parameterizations of the layered structure.

\subsubsection{Single Versus Joint Inversions}

[29] In the presence of noise, there is a trade-off between source depth and strength (Figure 6): a deep and strong source can look like a shallow weak source. When multiple interferograms (with different noise) are used in an inversion, the tradeoff for each individual interferogram is slightly reduced because of the additional data sets. For example, different inversions using only single interferograms give different source depths (Figure 6), but when the data are combined in a joint inversion, the range in inferred depths is narrower (Figure 5). For the level of noise in these interferograms, we find that for resolving source depth and strength at this volcano with data from ERS, it does not seem to matter whether the multiple interferograms are from different parallel orbital tracks (with slightly different viewing geometries) or the same one, as long as several interferograms are used. Using the joint results, we estimate that each location parameter (X, Y and depth) is accurate to about $1 \mathrm{~km}$, and that volume change is accurate to 0.05 units in log space (so that the absolute error scales with the size of the source). There is generally overlap between the misfit functions for each of the elastic media, but the minima can be different on the kilometer-scale, with differences depending on source depth (Figure 3).

\subsubsection{Effect of Topography}

[30] Local topographic variations can influence the inferred depth of a deformation source, principally because of the variable distance between the source and local relief [Williams and Wadge, 1998; Cayol and Cornet, 1998; Williams and Wadge, 2000]. A simple and generally effective method of accounting for the topographic effect is to use a source depth for each pixel in an interferogram, perturbed by the local elevation [Williams and Wadge, 1998]. We use this approximation to estimate source depth at all four actively deforming sources, and find that it changes the inferred source depth by less than $500 \mathrm{~m}$. Thus the effect of topography upon inferred source depth is less than the uncertainty in depth mentioned above. There is some doubt as to whether it is most appropriate to use the mean 
Geochemistry

T282: 12/00-5/96 (4.6 yr) T10: 12/99-10/95 (4.2 yr) T3: 4/00-10/97 (2.5 yr)

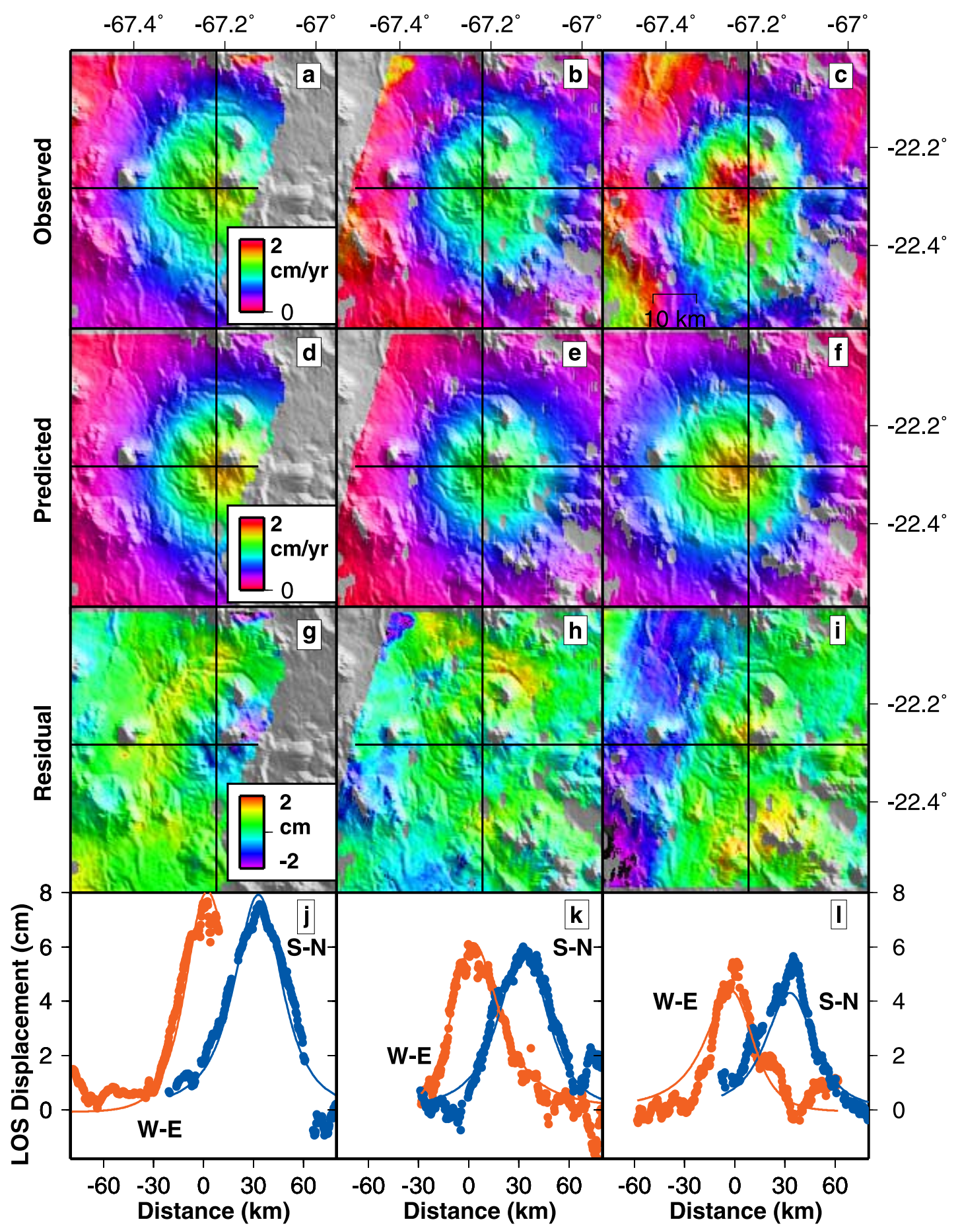

Figure 4. (a, b, c) Observed and (d, e, f) modeled rates of deformation $(\mathrm{cm} / \mathrm{yr})$ at Uturuncu in three independent interferograms, from two different tracks of descending InSAR data and one ascending track. The models were generated from a joint inversion using these three interferograms and two others. Black lines are the locations of profiles shown in the bottom row of the figure. The black lines run through the inferred center of the deformation source, and may appear offset from the center of the deformation pattern because of the projection of the deformation into the LOS. (g, h, i) Residual between data and model, shown as displacement. ( $\mathrm{j}, \mathrm{k}, \mathrm{l})$ South-north and west-east profiles through the model and data, where the south-north profile has been offset for the sake of clarity. Although the data fit is worse for ascending orbital track 3 than the other tracks, because there is only one ascending interferogram, it is not clear if the problem is real or an atmospheric artifact. 


$$
\text { Red }=\text { M2 ; Blue }=\text { M1; Black }=\text { Half-space }
$$
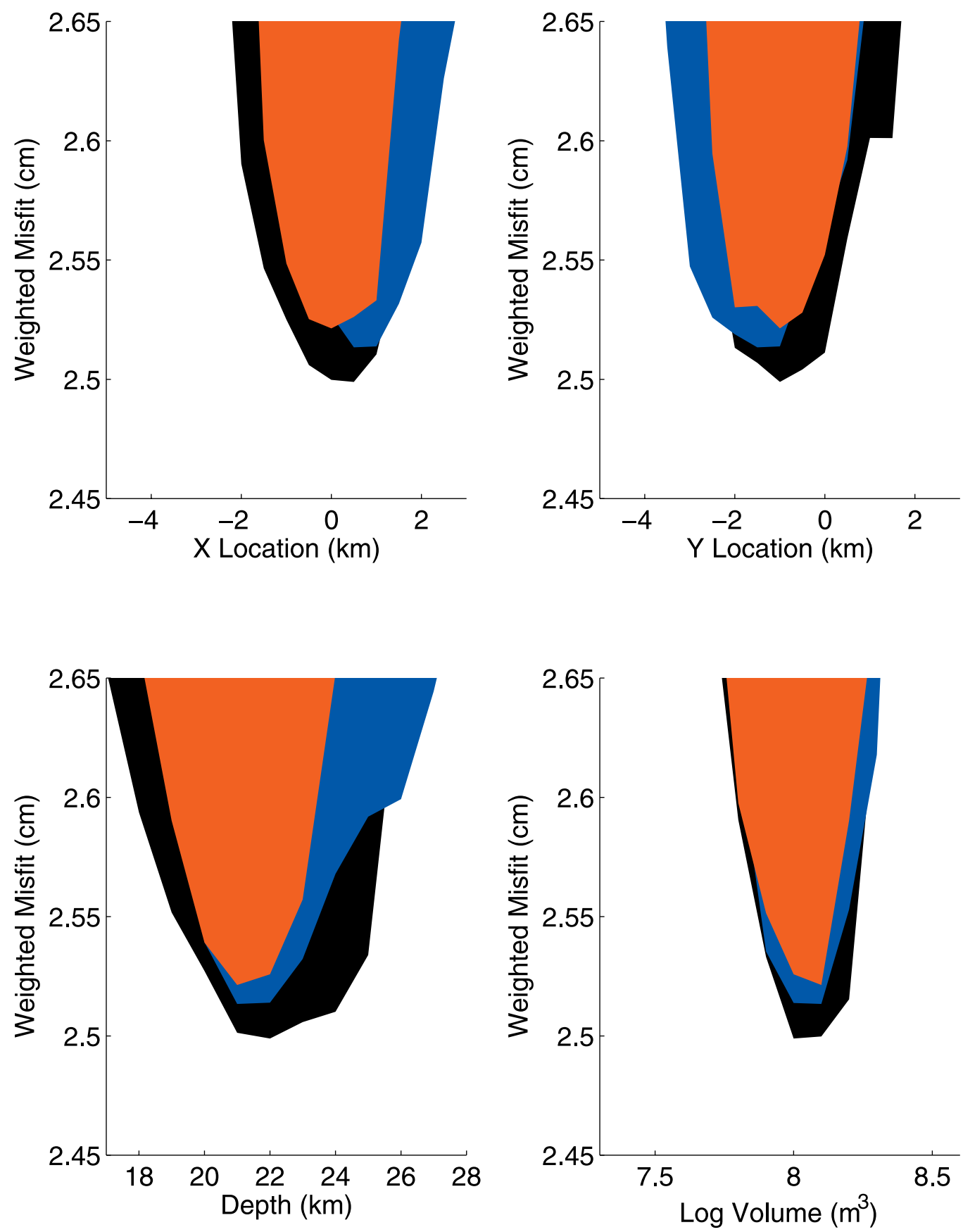

Figure 5. Scatterplot output from the NA inversions showing misfit as a function of model parameters for three elastic media - half-space, M1 and M2 (Figure 3). The misfit function is based on the L2 norm between data and the model, but is larger than the actual residual because it is calculated using a sub-sampled and weighted data set derived from our data subsampling program [Simons et al., 2002]. The depths are below the local reference elevation, and $4900 \mathrm{~m}$ should be subtracted to convert the depths relative to sea level. The best fitting depths for the models are: $22.2 \mathrm{~km}$ half-space; $21.9 \mathrm{~km} \mathrm{M}$; $21.7 \mathrm{~km} \mathrm{M}$. 

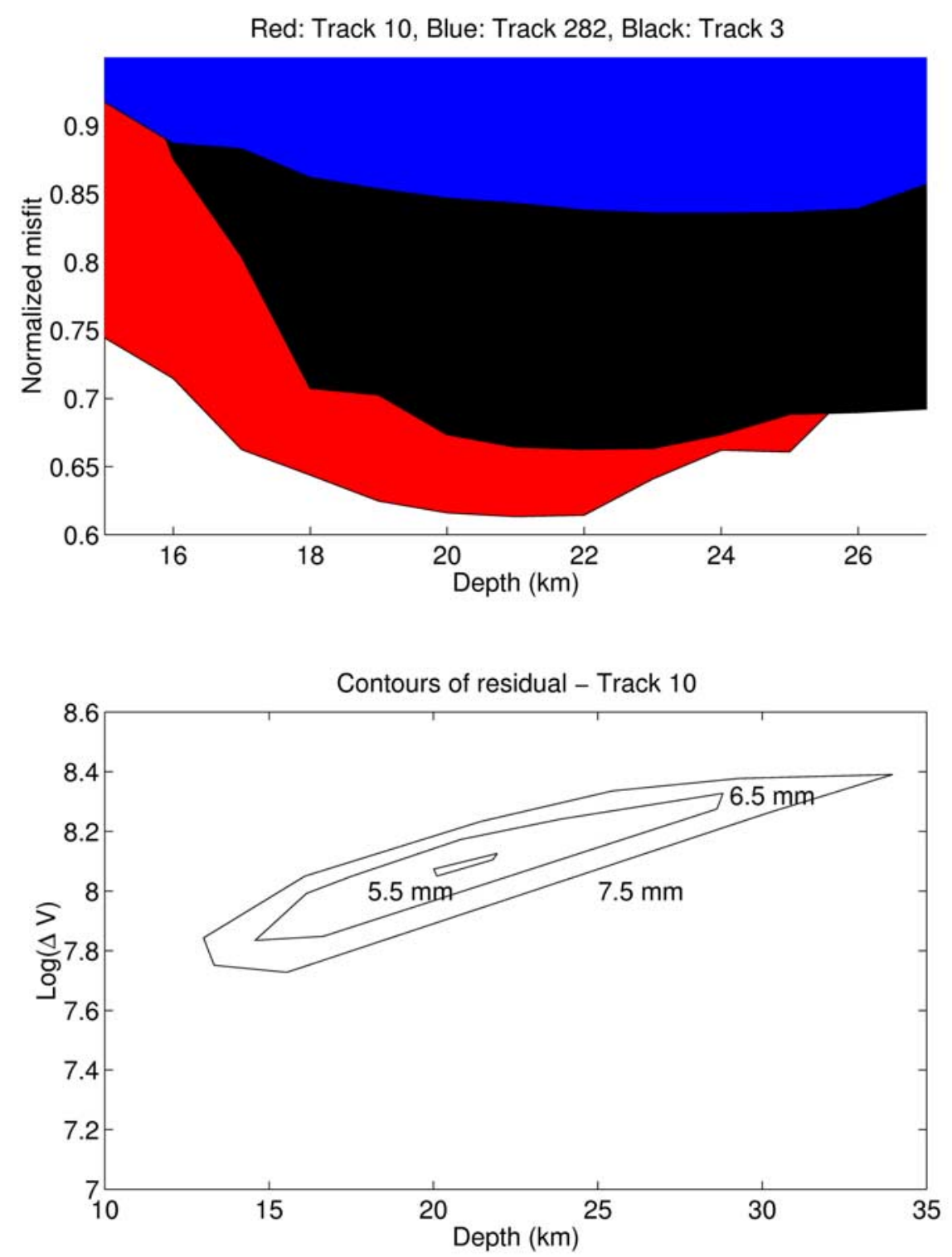

Figure 6. (top) Comparison of inferred source depth from inversion of three different satellite tracks at Uturuncu, done in separate inversions. Black is from ascending track 3, and has a best fit depth of about $22 \mathrm{~km}$ (relative to local reference elevation). Red is from descending track 10 with a best fit depth of about $21 \mathrm{~km}$, and blue is from descending track 282 with a best fit depth of $23-24 \mathrm{~km}$. Because the misfit for each orbit is different, the misfits have been normalized by the mean error for ease of comparison. (bottom) Contours of misfit plotted as a function of depth versus strength for an inversion using only a single interferogram from track 10 showing the trade-off between source depth and the source strength.

elevation (4.9 km for Uturuncu, see Table 3), or some other metric [Williams and Wadge, 1998], but this uncertainty is also of order $1 \mathrm{~km}$, and already included in our range of depths for each source. Considering the variation due to the elastic media, the effects of topography, and the width of the misfit function, we estimate the depth of a spheri- cal source for Uturuncu to be $16-18 \mathrm{~km}$ below sea level (21-23 km below the local surface).

\subsubsection{Effects of Source Geometry}

[31] Deformation from a shallow prolate ellipsoid with the semimajor axis nearly vertical can look similar to a deeper ellipsoid with the semimajor 
Table 3. Source Parameters for Different Geometries ${ }^{\mathrm{a}}$

\begin{tabular}{|c|c|c|c|c|c|}
\hline Volcano & & Uturuncu & Hualca Hualca & Lazufre & Cerro Blanco \\
\hline \multirow{4}{*}{$\begin{array}{c}\text { Location (Lat, Lon) } \\
\text { Spherical }\end{array}$} & & $-22.265,-67.185$ & $-15.73,-71.86$ & $-25.33,-68.52$ & $-26.77,-67.72$ \\
\hline & $X$ & -3.5 & 1.4 & 1.2 & -0.6 \\
\hline & Y & -2 & 0.7 & 6.5 & -1.5 \\
\hline & $\mathrm{Z}$ & 17.3 & 13 & 7.3 & 4.8 \\
\hline \multirow[t]{6}{*}{ Horizontal Ellipsoid } & $\mathrm{X}$ & -1.5 & 1.37 & 1.6 & -1.1 \\
\hline & $\mathrm{Y}$ & -1.4 & 1.5 & 6.1 & -1.6 \\
\hline & Z & 18.8 & 12.5 & 9.8 & 7 \\
\hline & $\theta$ & 2.9 & 1.7 & -1.2 & 0.6 \\
\hline & $\phi$ & 77.9 & 91.7 & 112 & 244 \\
\hline & $\mathrm{a} / \mathrm{b}$ & 6.4 & 1.0 & 9.5 & 5.7 \\
\hline \multirow{6}{*}{ Vertical Ellipsoid } & $\mathrm{X}$ & -3.2 & -1.3 & -2.9 & -0.4 \\
\hline & $\mathrm{Y}$ & -1.4 & 1.0 & 7.6 & -0.5 \\
\hline & Z & 18.2 & 7.8 & 6.4 & 5.6 \\
\hline & $\theta$ & 100 & 77.4 & 66.0 & 72.4 \\
\hline & $\phi$ & 286 & 90.8 & 109 & 233 \\
\hline & $\mathrm{a} / \mathrm{b}$ & 1.0 & 1.7 & 4.3 & 1.2 \\
\hline \multirow[t]{4}{*}{ Point Crack } & $X$ & -3.1 & 9.7 & 5.6 & 2.3 \\
\hline & Y & -1.6 & -1.0 & 5.7 & -2.3 \\
\hline & Z & 25 & 18.1 & 12.8 & 9.7 \\
\hline & radii & 0.4 & 1.1 & 1.0 & 1.0 \\
\hline \multirow[t]{4}{*}{ Finite Crack } & X & -3.3 & 3.1 & 5.4 & 0.3 \\
\hline & $\mathrm{Y}$ & -1.7 & 4.6 & 5.5 & -1.2 \\
\hline & Z & 12 & 10 & 5.2 & 5.8 \\
\hline & radii & 21 & 16.0 & 13.4 & 7.4 \\
\hline
\end{tabular}

\footnotetext{
${ }^{\mathrm{a}}$ List of best fitting source locations for each actively deforming volcano for different source geometries in an elastic halfspace. The location of the volcano is the latitude and longitude of the volcanic edifice, $\mathrm{X}$ and $\mathrm{Y}$ indicate the source location relative to that position, and $\mathrm{Z}$ is the depth below sea level. The mean elevation above sea level in the vicinity of the sources of active deformation is as follows: $5 \mathrm{~km}$ at Hualca Hualca; $4.9 \mathrm{~km}$ at Uturuncu; $4.8 \mathrm{~km}$ at Lazufre; and $4.2 \mathrm{~km}$ at Cerro Blanco. All X, Y, Z locations and radii are in km. The latitude and longitude for Lazufre is at the center Cordon del Azufre, so the source is NE of that volcano. The volume of inflation or deflation in the source varies between interferograms, see Figure 9. The data from this table (including the location of spherical sources in a layered-space) is shown in Figure 8. The minimum depth of the finite crack is not sharply defined (particularly at Hualca Hualca), and we pick a representative value that explains the data.
}

axis nearly horizontal (and with a different ratio of the semimajor to semiminor axis). Because dips within about 20 degrees of horizontal and vertical look similar, we include this range when we refer to horizontal and vertical prolate ellipsoids. Prolate ellipsoids with other dips lie at depths in-between these extremes. For the penny-shaped crack, the shallowest models have a large ratio between crack radius and depth and are called finite cracks. As the ratio of radius to depth decreases and approaches a "point crack," the depth of the best-fitting source increases. Using data from both ascending and descending satellite tracks (at Uturuncu) can restrict the range in dips of the prolate ellipsoids, and constrains a vertical prolate source to have a spherical aspect ratio. All types of models (vertical and horizontal ellipsoids and finite and point cracks) fit the data equally well (Figure 7), and the depths of these sources span nearly $10 \mathrm{~km}$
(Table 3). A wider range of prolate ellipsoids (with dips between nearly vertical and horizontal) are permitted at the other sources because we only have good observations from descending satellite tracks. We have not attempted to determine all source geometries that explain the data, but instead pick end-member models to show plausible extremes in source depth (Table 3 and Figure 8).

\subsubsection{Time Dependence}

[32] Using InSAR deformation data, we can constrain the rate of source volume change as a function of time (Figure 9) or the volume within the chamber as a function of time from the first InSAR observation (Figure 10). For both we assume a constant source depth (see Table 3 for depths), and a spherical source in a half-space. At a given source depth, the inferred volume change depends only slightly on source geometry, and the 


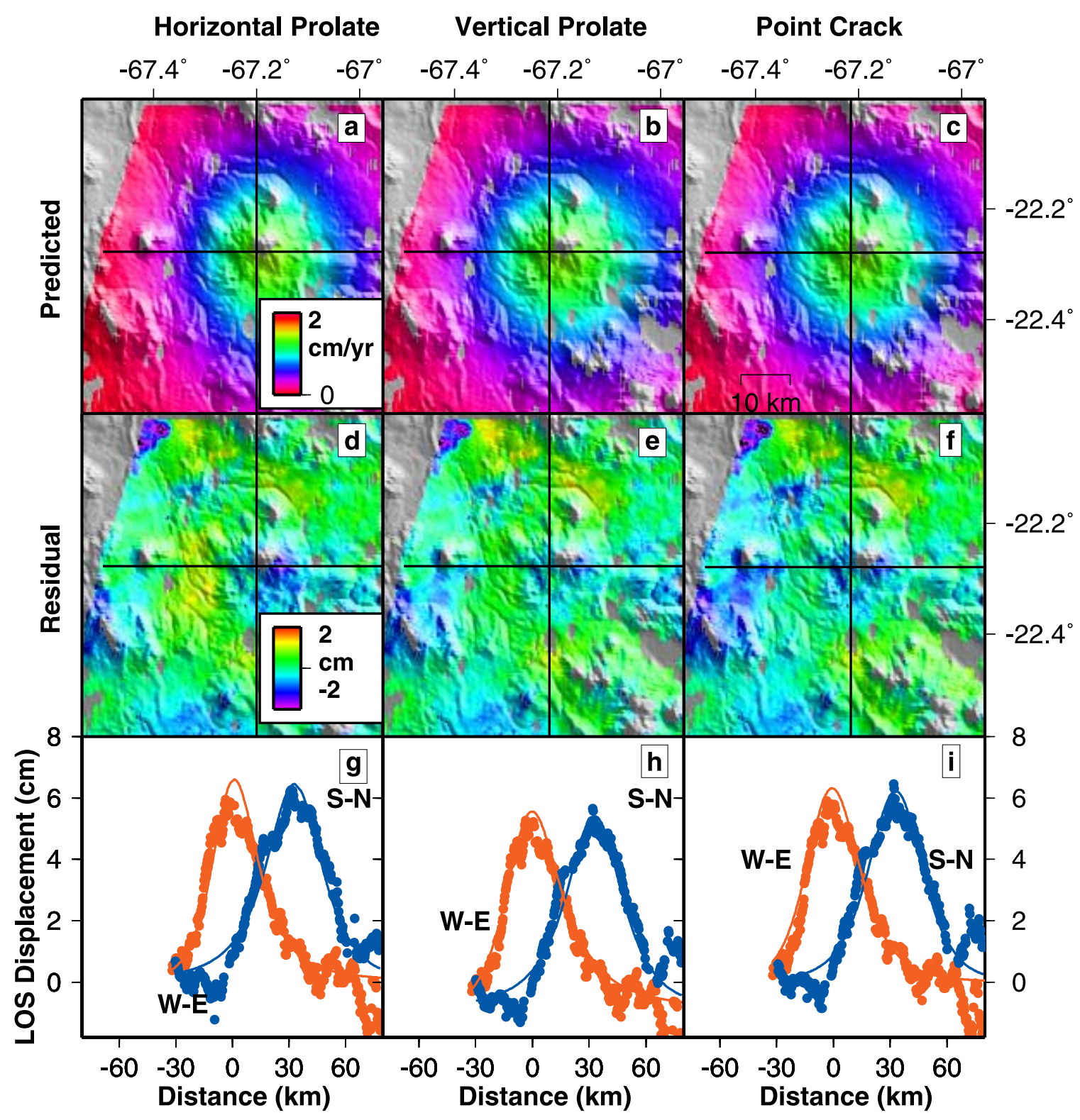

Figure 7. ( $\mathrm{a}, \mathrm{b}, \mathrm{c})$ Modeled rates of deformation $(\mathrm{cm} / \mathrm{yr})$ at Uturuncu from descending track 10 (same data as in Figure 4) from different source geometries: horizontal prolate (Figure 7a), vertical prolate (Figure 7b), point crack (Figure 7c). Results for a spherical point source in a half-space are shown in Figure 4. To generate the models, between two and five interferograms were used in joint inversions. Black lines are location of profiles shown in the bottom row of the figure. (d, e, f) Residual between data and model, shown as displacement. (g, h, i) South-north and west-east profiles through the model and data, where the south-north profile has been offset for the sake of clarity.

majority of our best best-fitting nonspherical sources lie within the plotted error bars. Of course, because of the trade-off between source depth and strength, if the model is at one of the extremal values (e.g., finite or point crack) all of the volumes in Figure 9 could be shifted up or down by a factor less than a factor of two (depending on the deformation center). In addition, all volume estimates could be systematically effected by perhaps $20 \%$ if the elastic medium is non-Poissionian [ $L u$ et al., 2003b]. For the plot of rates (Figure 9), we assume a constant rate of deformation during the time period covered in the interferogram. To make Figure 10, we use the overlapping interferograms 


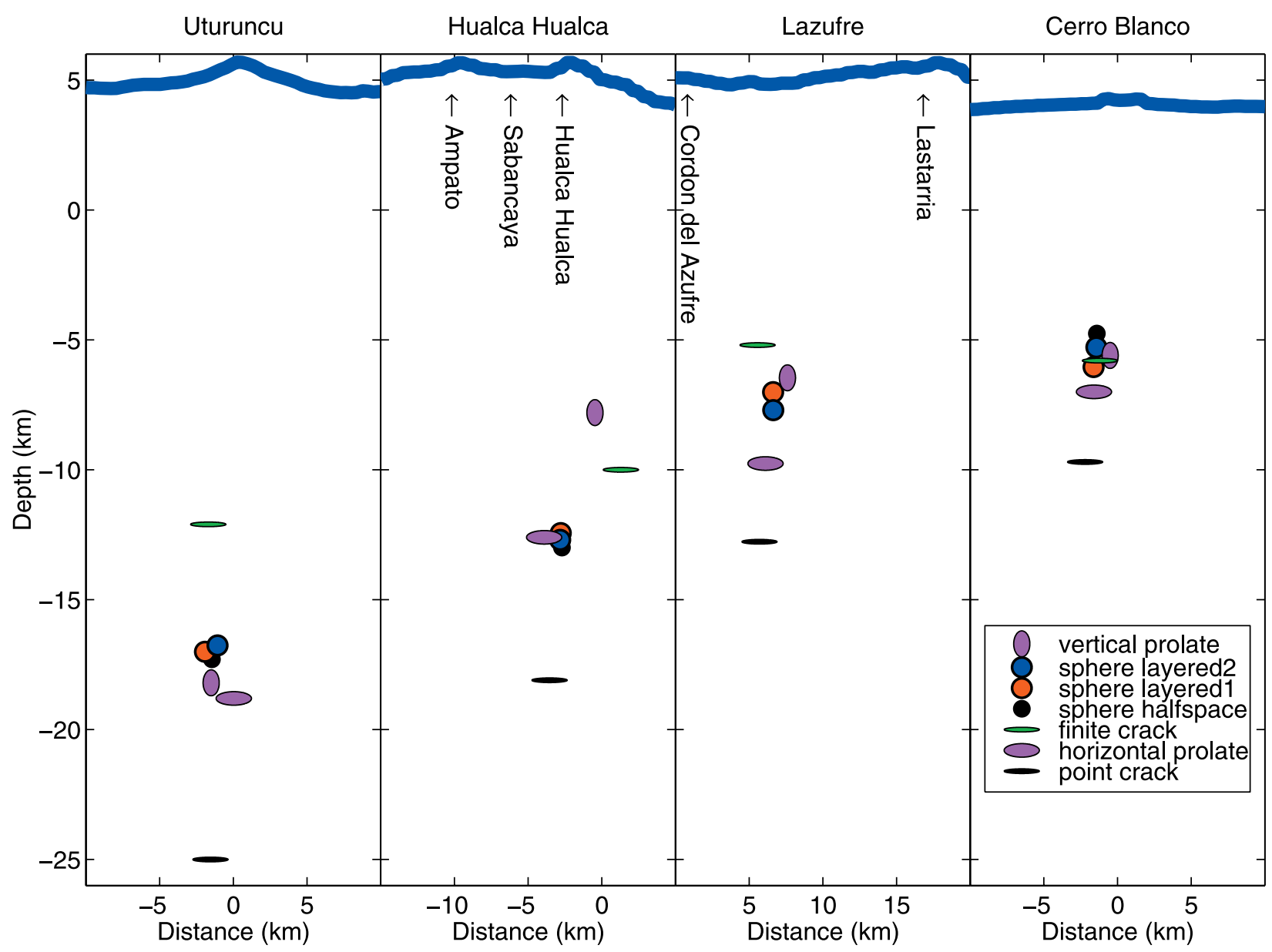

Figure 8. North-south profiles at the four deformation centers showing the topography and the inferred location and depths for the spherical, ellipsoidal and crack sources of deformation (see Table 3 for details of the sources used). The ellipsoidal and crack sources were calculated in a half-space while the spherical sources were calculated using both layered- and half-space crustal models. The inversions for the spherical sources were done using NA, while the conjugate gradient methods were used for the nonspherical sources (see text). Between two and five interferograms were jointly inverted to determine the source parameters. The models shown are intended to be end-members and do not represent all possible sources that can explain the deformation.

to do a linear least squares inversion for the volume change during the time interval between each SAR acquisition [e.g., Lundgren et al., 2001], and assume that the deformation rate is constant during these intervals. There is a suggestion that the inferred rate of volume change in the magma chamber below Uturuncu slightly increases in 1998 [Pritchard et al., 2002, Figures 9 and 10]. An increase at about the same time is more apparent at Lazufre and is discussed more below.

\subsubsection{Seismicity}

[33] The high rate of seismicity at Uturuncu mentioned earlier (many events per hour) is surprising considering the low rate of seismicity at other dormant volcanoes. InSAR has been used to detect noneruptive deformation at South Sister, Oregon [Wicks et al., 2002], Westdahl, Aleutians [Lu et al., 2000d], and Mount Peulik, Alaska [Lu et al., 2002a]. The last eruption of Westdahl was in 1991, of Peulik was in 1814, and no historic eruptions are known for South Sister. There are seismic arrays at Westdahl and South Sister, and Mount Peulik is $50-70 \mathrm{~km}$ from a seismic array associated with Mount Katmai. The rate of seismicity at these volcanoes seems to be a few events a year or less (e.g., http://www.geophys. washington. edu/SEIS/PNSN/SISTERS/;S.McNutt, 


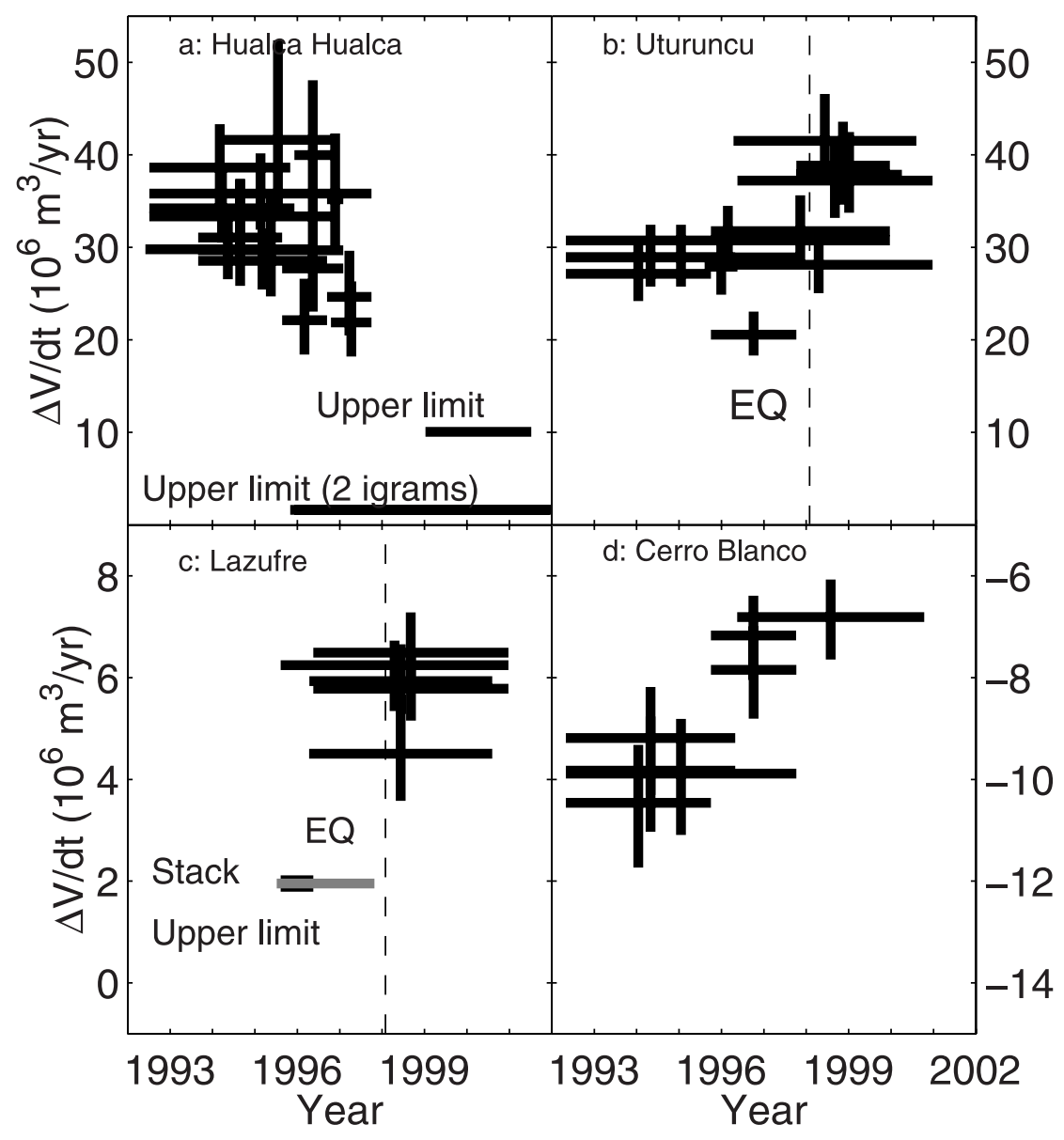

Figure 9. Inferred rate of volume change as a function of time, assuming a constant source depth at each location, a spherical source in a half-space, and a constant rate of deformation during the time period covered in the interferogram. The horizontal bar shows the time period covered by the interferogram and the vertical bar reflects an estimate of the error on the inferred rate of volume change. The error bar is 0.05 units in log space (so that the absolute error scales with the size of the source), except for InSAR scenes with extensive atmospheric contamination at Hualca Hualca where the error was estimated to be $0.10 \log$ units (see text). The vertical error bar has been estimated by examining the spread in the scatterplot of misfit as a function of source strength, comparing the strength results from inversions of different combinations of data sets, and comparing interferograms that span nearly the same time interval, including a set of interferograms at Cerro Blanco that differ by only 1 day (made using a tandem pair). (a) Hualca Hualca. (b) Uturuncu: the time of a $1998 M_{w} 7.1$ earthquake is shown as dotted line. (c) Lazufre: the time of the earthquake is shown as a dotted line. (d) Cerro Blanco.

personal communication, 2003; Dixon et al. [2002]). Perhaps the higher rate of seismicity at Uturuncu is related to groundwater movements.

\subsubsection{Hualca Hualca}

[34] This edifice is a member of a group of three stratovolcanoes, (Ampato and Sabancaya are the others) in southern Peru. Sabancaya is the youngest and is the most active. Recent activity at Sabancaya began with increased fumarolic and seismic activ- ity in 1985-1986, a major period of eruptions between May 1990 and early 1992 [e.g., Smithsonian Institute, 1988, 1990a, 1990b, 1990c, 1991a, 1991b; de Silva and Francis, 1991; Chorowicz et al., 1992; Simkin and Siebert, 1994; GonzalezFerran, 1995], and several small eruptions and persistent fumarolic activity throughout the 1990s [Smithsonian Institution, 1994a, 1995, 1997a, 1998a, 1998b, 1998c, 2000a] that has led to melting of its ice cap. The only documented activity 


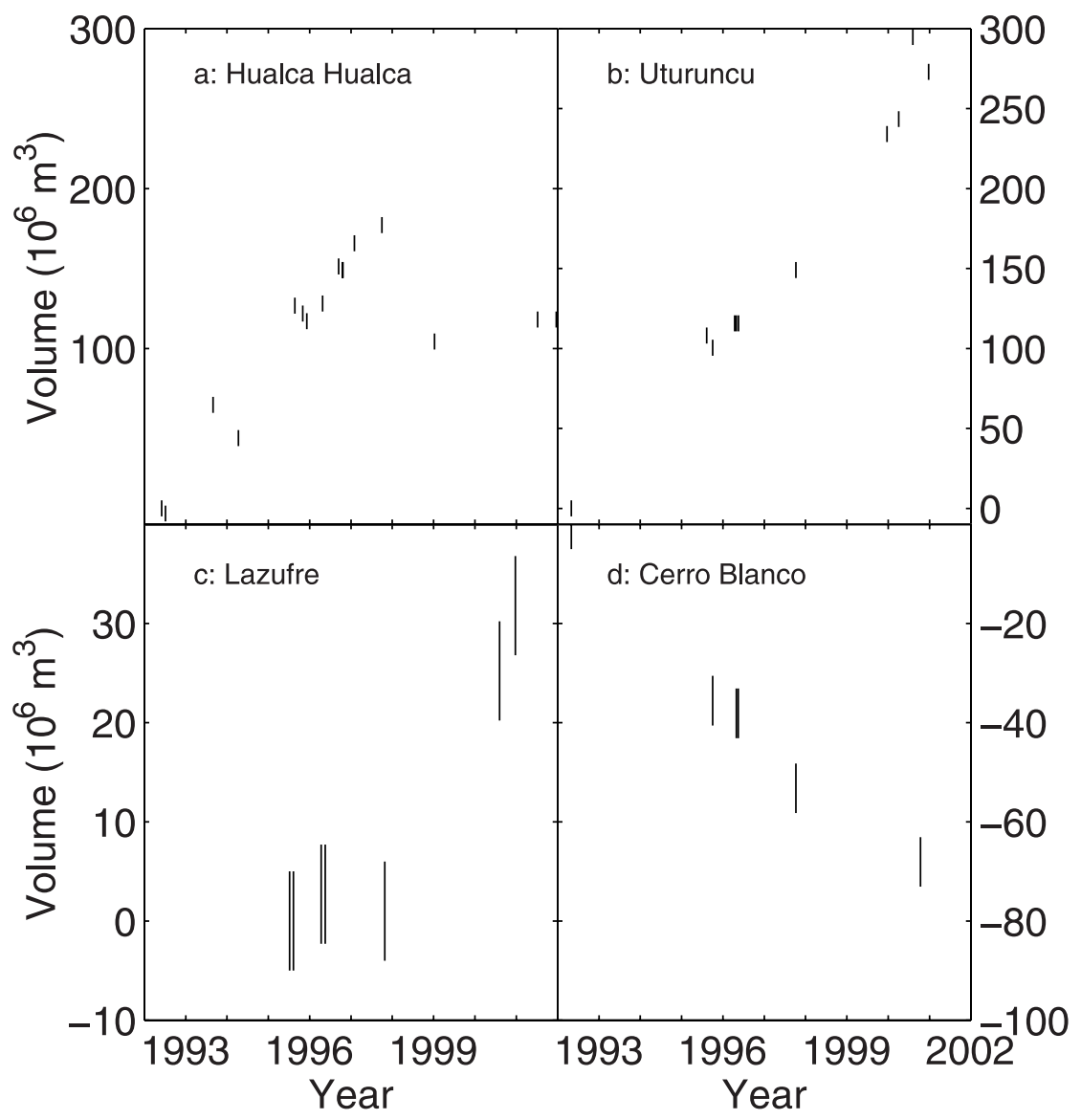

Figure 10. Volume inferred to be in each magma chamber as a function of time, assuming zero volume at the time of the first SAR image. Using the overlapping interferograms, we estimate the rate of deformation between each pair of SAR images with a linear least squares inversion. We plot the result as the cumulative volume within the source at the time of each SAR image. We assume a constant error for each inversion result of $5 \times 10^{6} \mathrm{~m}^{3}$.

at Hualca Hualca is fumarolic [Gonzalez-Ferran, 1995].

[35] We show the data, model, residual and profiles for Hualca Hualca from three interferograms from the same satellite track in Figure 11. Within error, Hualca Hualca has an approximately constant rate of inflation prior to 1997 (Figures 9 and 10). No deformation is seen in three interferograms spanning times after 1997, and because these interferograms also span times with known inflation, there is an apparent deflation of the source between 1997 and 1999 (Figure 10). Of all the deformation centers we observed, atmospheric contamination was most evident in a few interferograms from Hualca Hualca. As an example, Figure 12 shows the correlation of residual phase with topography at Chachani volcano, about $30 \mathrm{~km}$ from Hualca
Hualca. Several factors suggest that this signal is due to atmospheric effects: (1) the residual appears in some interferograms, but not others that cover nearly the same time interval (Figure 12); (2) The signal changes sign in temporally overlapping interferograms; (3) The magnitude of the signal seems to be independent of the time interval.

[36] To model the source of deformation, we first used the three independent interferograms in Figure 11 that showed no significant correlation between variations in phase and topography to constrain the source location. Using the calculated location, we inverted the interferograms with atmospheric artifacts for source strength and a ramp with topographic dependence (i.e., solved the equation $\phi(x, y, z)=a x+b y+c z+d$, where $x, y$ are horizontal coordinates and $z$ is the elevation), 
Geochemistry

T454: 10/97-7/92 (5.2 yr) T454: 4/96-6/92 (3.9 yr) T454: 9/96-8/93 (3.0 yr)

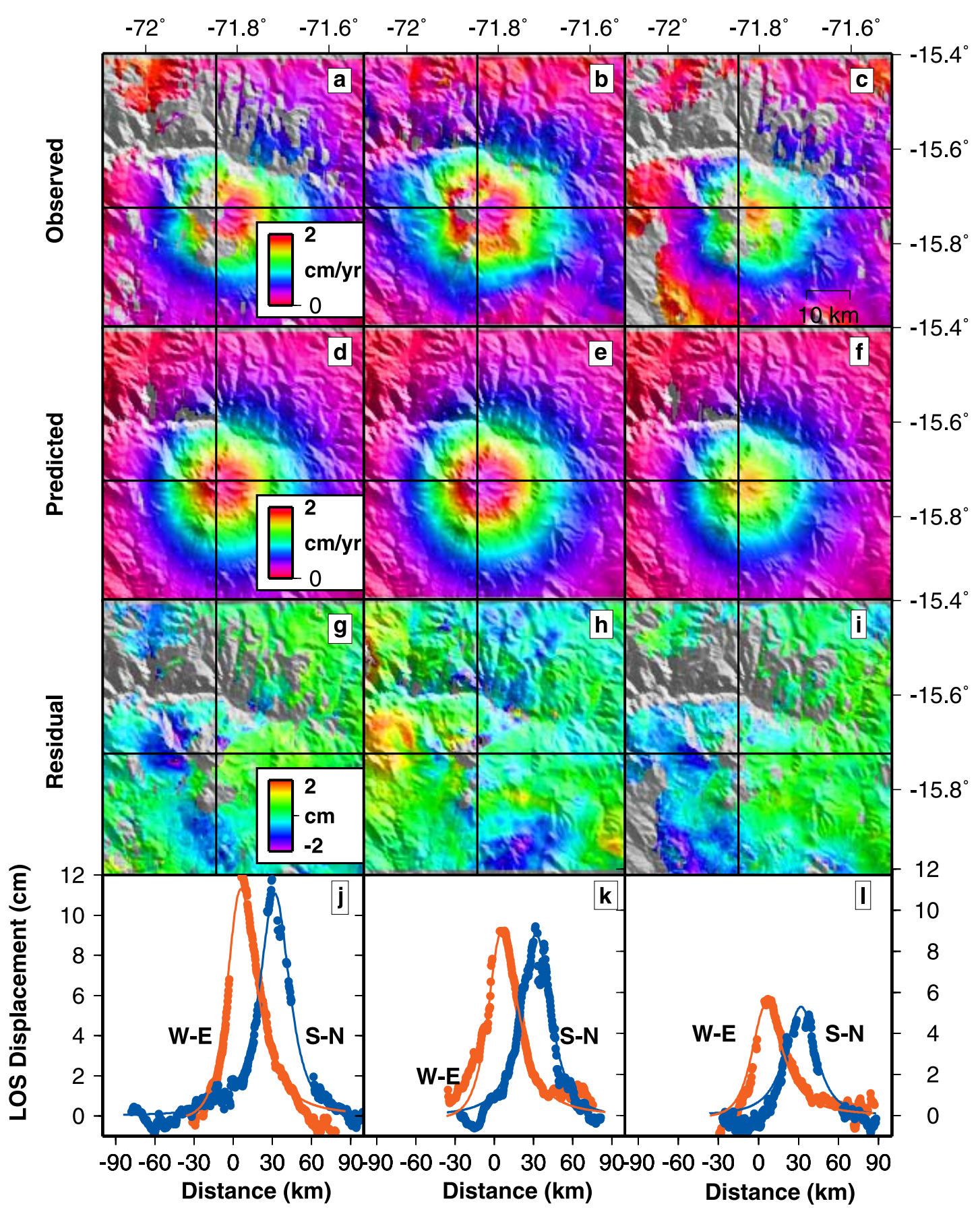

Figure 11. (a, b, c) Observed and (d, e, f) modeled rates of deformation ( $\mathrm{cm} / \mathrm{yr})$ at Hualca Hualca in three independent interferograms, all taken from the same track of descending InSAR data. We jointly inverted these three interferograms to determine the source location. Black lines show location of profiles shown in the bottom row of the figure. (g, h, i) Residual between data and model, shown as displacement. (, $\mathrm{k}$, l) South-north and west-east profiles through the model and data, where the south-north profile has been offset for the sake of clarity. A region of localized subsidence can be seen in the raw data, residual and south-north profiles, to the N-NE of Hualca Hualca (Figures 11a, 11b, 11g, 11h, 11j, and 11k), and might be caused by an earthquake during the common time period (24 August 1995 to 31 August 1993). Pritchard [2003] inverts the residual for the best earthquake mechanism, and finds a magnitude and mechanism similar to an event on 26 December 1994, but both the horizontal location and depth are are 10-45 km from the catalog locations. Alternatively, the residual could be related to fumarolic activity [Pritchard, 2003]. 

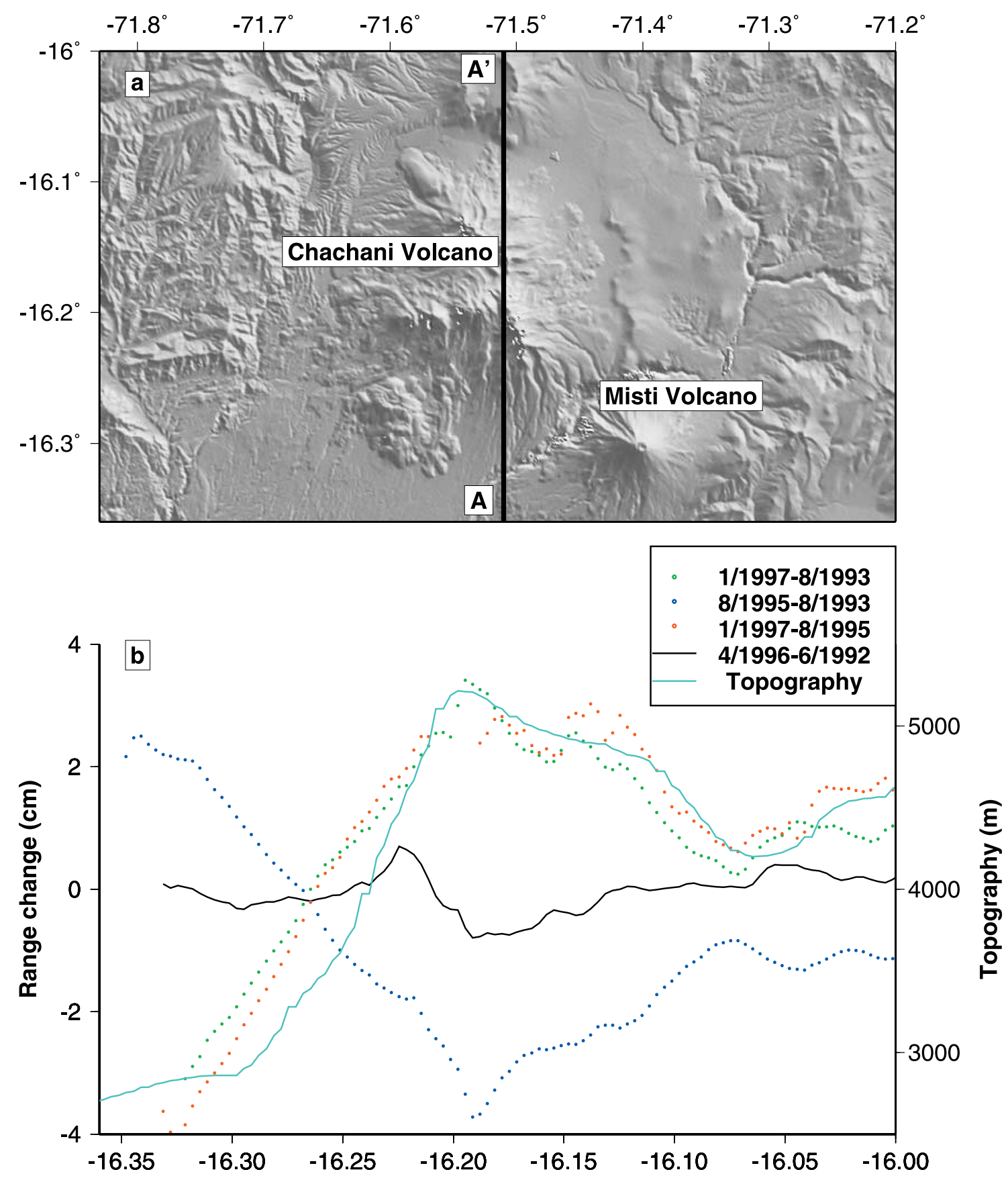

Figure 12. Profiles through several interferograms in southern Peru (track 454, frame 3925) showing residual phase correlated with topography, presumably related to atmospheric effects. (a) Regional topography near location of profiles (black lines) over Chachani volcano about $30 \mathrm{~km}$ SE of Hualca Hualca. (b) Profiles from 4 interferograms and topography. Dotted lines are from interferograms that show a correlation between range change and topography and the solid line is from an example interferogram with little correlation between range change and topography.

an approach that has been used in previous studies [e.g., Feigel et al., 2002; Hoffmann, 2003]. The parameter $c$ is of order $1-1.5 \mathrm{~cm} / \mathrm{km}$, and does not explain all of the tropospheric signal in Figure 12, since the signal is not purely correlated to topog- raphy. Because there is a potential trade-off between $c$ and the inferred volume change, there are larger errors in our estimates of volume change for interferograms with obvious atmospheric contamination (Figure 9). 


\subsubsection{Lazufre}

[37] A surprising result of this survey is the discovery of a source of deformation not associated with any known edifice, but lying between between the "potentially active" centers of Lastarria and Cordon del Azufre [de Silva and Francis, 1991], along the border between Chile and Argentina. No activity has been recorded at Cordon del Azufre, but fumarolic activity has been observed at Lastarria [de Silva and Francis, 1991]. The northernmost crater is the most active [Gonzalez-Ferran, 1995]; in fact, activity at Lastarria is thought to be generally migrating to the north [Naranjo and Francis, 1987], while the observed deformation is to the south. Lastarria has been more studied than Cordon de Azufre, because of its unusual sulphur lava flows [Naranjo, 1985], and large debris avalanche [Naranjo and Francis, 1987]. No active fumaroles were observed at Cordon del Azufre, or in the vicinity of the Lazufre magma body during a field visit in October, 2002 [Pritchard, 2003]. The activity at Lastarria in October, 2002 seems similar to that observed in the late 1980 s (J. Naranjo, personal communication, 2002). We have made 7 interferograms from a single track of descending ERS data spanning 8 July 1995 to 24 December 2000. We do not observe deformation in two interferograms spanning times before 1998, but we see deformation at a rate of at least $1 \mathrm{~cm} / \mathrm{yr}$ (because the deformation was not uniform in time) in the LOS is seen in three interferograms spanning 1995-2000 and 19962000.

[38] Figure 13 shows data, model, residual and profiles for two interferograms at Lazufre. Compared to predictions from a spherical model, the observed deformation looks slightly aspherical, elongated in the NE-SW direction. The best-fitting prolate ellipsoid improves the fit, but the decrease in residual (about 5\%) is small considering the number of additional parameters used (e.g., five for the spherical source versus nine for the ellipsoidal source when only a single interferogram is used).

[39] Figure 9 shows the inferred volume change in the magma source region over the time period when data was available (7/1995-12/2000). Unfortunately, only one track of radar data is available (with seven interferograms) for Lazufre, and this track has only limited temporal coverage. However, even with this limitation, the data suggest time-dependence of the deformation, with no deformation apparent in two stacked interferograms before the beginning of 1998, and a clear signal in three interferograms after that time (Figure 10). The temporal coverage is insufficient to resolve whether the start of deformation was abrupt or gradual. We note that there also seems to be an increase in the rate of inflation at Uturuncu, at about the same time. While the increase in inflation rate could be coincidental, a $M_{w} 7.1$ subduction zone earthquake occurred near the time of the increase at both locations (30 January 1998). Changes in the activity level of volcanic centers associated with earthquakes has been documented before [e.g., Johnston et al., 1995]. Of the deforming volcanoes we observe, Uturuncu and Lazufre are the closest to this earthquake (about 400 and $300 \mathrm{~km}$, respectively). However, the triggering hypothesis is questionable since none of the volcanoes were obviously effected by the $M_{w} 8.1$ Antofagasta earthquake (30 July 1995) in about the same location as the 1998 event.

\subsubsection{Cerro Blanco (Robledo)}

[40] This caldera, located in northwest Argentina, is unusual among the actively deforming volcanoes because it is subsiding. The caldera is called Cerro Blanco on Argentinian maps (J. Viramonte, personal communication, 2002), but called Robledo in the Smithsonian Institute's database [Simkin and Siebert, 1994]. de Silva and Francis [1991] call the caldera Robledo and the silicic dome in the southwest corner of the caldera Cerro Blanco. Henceforth, we call the caldera Cerro Blanco. We have made 7 interferograms from 2 descending tracks spanning 2 May 1992 to 12 October 2000.

[41] The data, model, residual and profiles for three interferograms from two different satellite tracks at Cerro Blanco spanning 5/1992-10/2000 are shown in Figure 14. The rate of subsidence seems to decrease with time from a maximum of 
T282: 8/00-4/96 (4.3 yr) T282: 12/00-5/96 (4.6 yr)

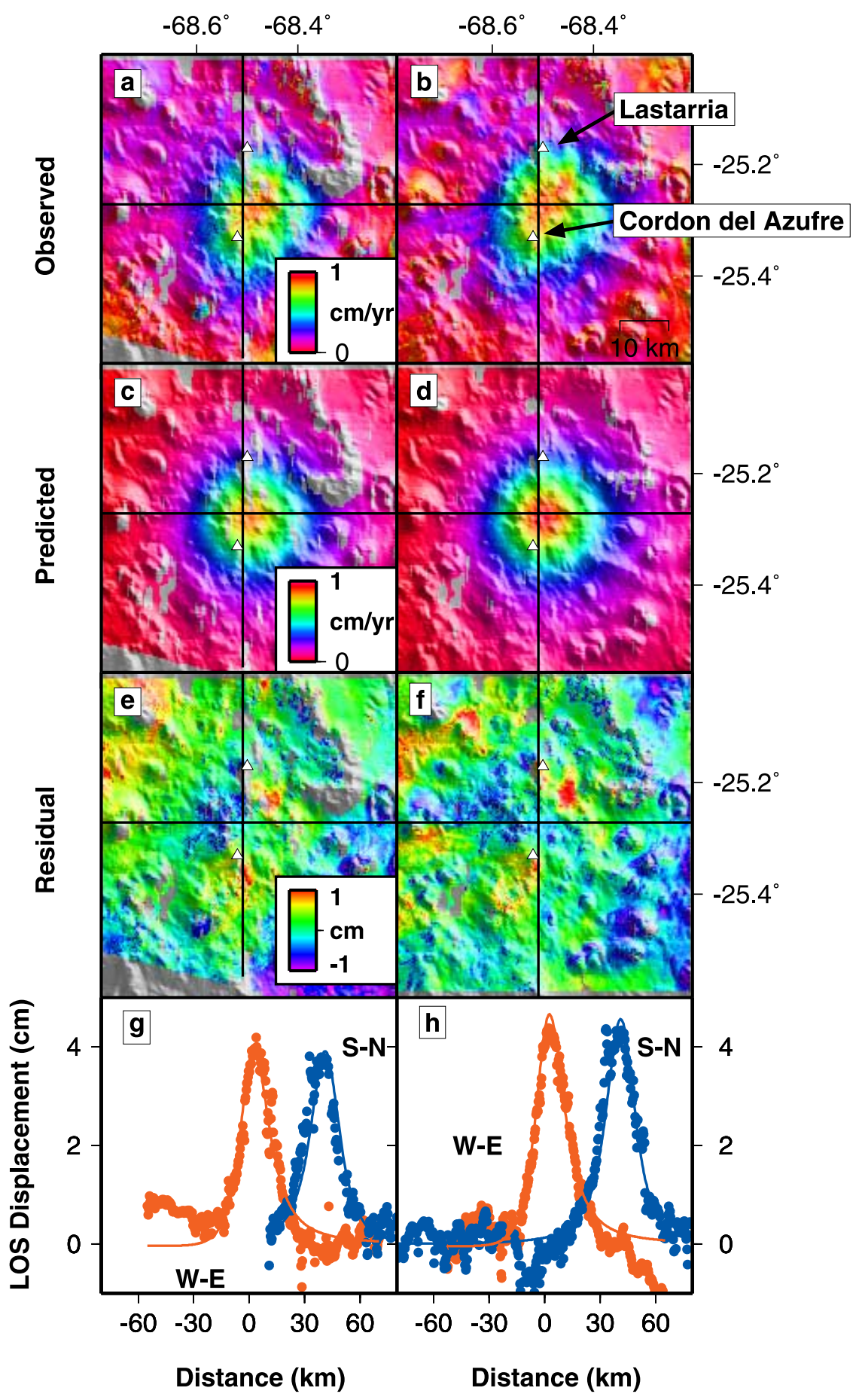

Figure 13. (a, b, c) Observed and (d, e, f) modeled rates of deformation $(\mathrm{cm} / \mathrm{yr})$ at Lazufre (between Lastarria and Cordon del Azufre: these volcanoes are shown as white triangles) in two independent interferograms, taken from the same track of descending InSAR data. These two interferograms were inverted jointly for the source location. Black lines are location of profiles shown in the bottom row of the figure. (g, h, i) Residual between data and model, shown as displacement. There are small, consistent residuals NE and SW of the deformation center, and these features remain even with the best-fitting axisymmetric prolate and oblate sources. We suspect that the residual is atmospheric contamination related to topographic changes. $(\mathrm{j}, \mathrm{k}, \mathrm{l})$ South-north and west-east profiles through the model and data, where the south-north profile has been offset for the sake of clarity. 
Geochemistry

T239: 10/00-5/96 (4.4 yr) T10: 10/97-5/92 (5.4 yr) T10: 4/96-5/92 (4 yr)

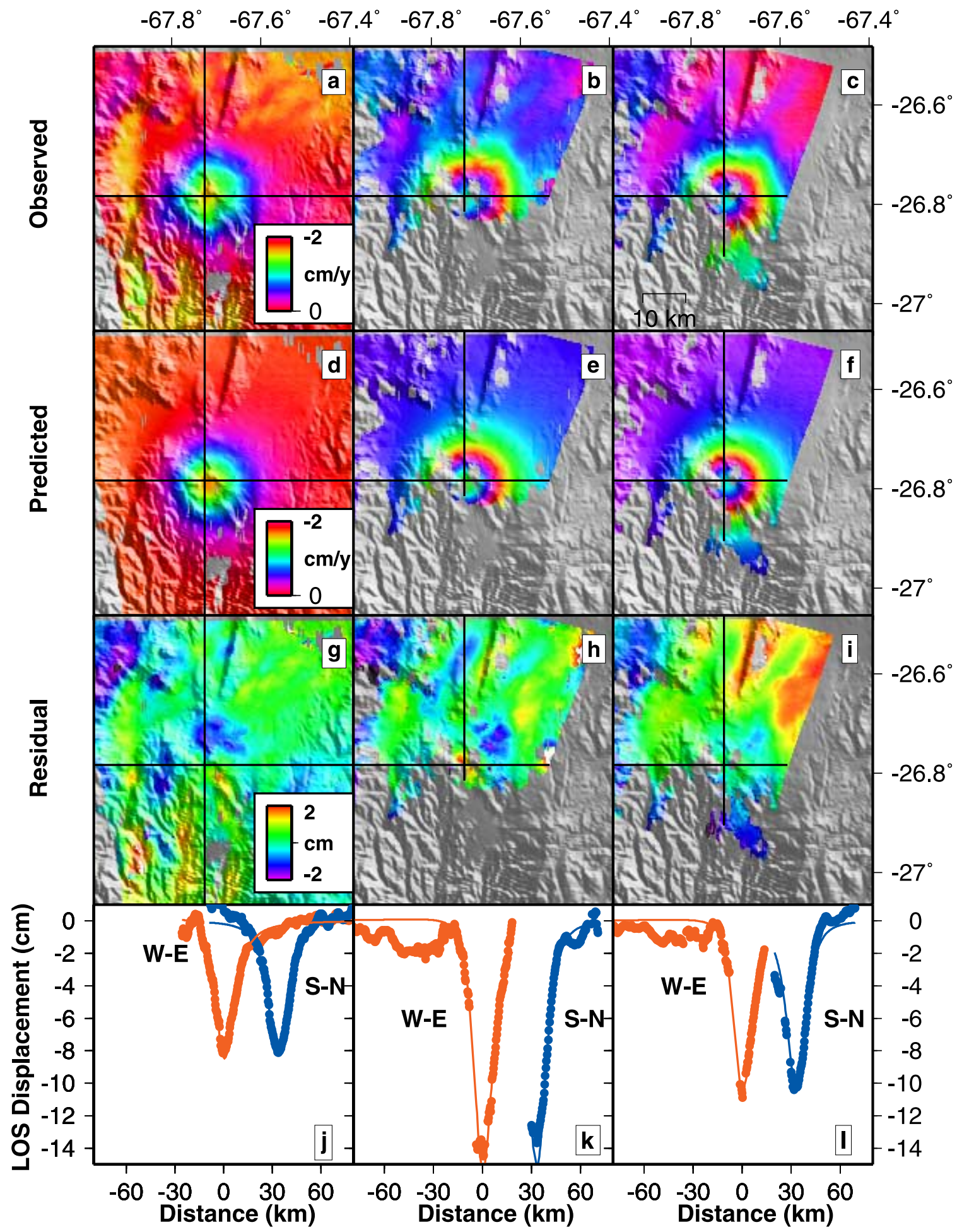

Figure 14. ( $\mathrm{a}, \mathrm{b}, \mathrm{c})$ Observed and $(\mathrm{d}, \mathrm{e}, \mathrm{f})$ modeled rates of deformation $(\mathrm{cm} / \mathrm{yr})$ at Cerro Blanco in three interferograms, taken from two tracks of descending InSAR data. The source location was determined by a joint inversion using these three interferograms. Black lines are locations of profiles shown in the bottom row. (g, h, i) Residual between data and model, shown as displacement. ( $, \mathrm{k}, \mathrm{l}$ ) South-north and west-east profiles through the model and data, where the south-north profile has been offset for the sake of clarity. 
more than $2.5 \mathrm{~cm} / \mathrm{yr}$ in the radar LOS (interferograms spanning 1996/7-1992) to less than $1.8 \mathrm{~cm} / \mathrm{yr}$ (2000-1996, Figures 9 and 10).

\subsection{Selected Nondetection}

\subsubsection{Chiliques}

[42] Nighttime thermal infrared images taken by the ASTER (Advanced Spaceborne Thermal Emission and Reflection Radiometer) instrument on the Terra satellite indicated a thermal anomaly at Chiliques volcano (a Chilean stratovolcano within our study region) on 6 January 2002, but not on 24 May 2000 (http://www.jpl.nasa.gov/releases/ 2002/release_2002_85.html). Our further analysis of the ASTER nighttime thermal infrared images indicates that the thermal anomaly was probably short-lived. An anomaly was seen on 5 April 2002, but no anomalies were seen between May-September, 2000 (data from 7/27, 8/12, and 9/13) or MayJuly, 2002 (data from 5/23, 6/15, 6/24, 7/17). No features were seen in any of the six short-wavelength infrared bands, indicating a low-temperature thermal anomaly, and a more detailed study is underway (M. Abrams, personal communication, 2002). No fumarolic activity was seen during a field visit to the base of Chiliques in October 2002, or was noted by the villagers of Socaire, $15 \mathrm{~km}$ from Chiliques and the closest settlement to the volcano (J. Naranjo and J. Clavero, personal communication, 2002). No deformation is observed at Chiliques between 5/1992-12/2001 (Figure 15).

\subsection{Eruptions}

\subsubsection{Lascar}

[43] Lascar, Chile, is currently the most active volcano in the central Andes, and although it has had several major and minor eruptions during the period when InSAR data are available, no preeruptive, co-eruptive, or posteruptive deformation has been observed [Pritchard and Simons, 2002]. Here we provide more details of our observations of Lascar, including higher quality interferograms made with DEMs from SRTM, and discuss the possible explanations for the lack of deformation.

[44] Lascar was first observed to be active in 1848 , and the activity intensified in 1984. Since then, there have been several cycles of activity culminating in eruptions that have been monitored on the ground, in the air, and in space [Oppenheimer et al., 1993; Matthews et al., 1997; Wooster and Rothery, 1997; Wooster, 2001]. Lascar has persistent fumarolic activity and an unusual harmonic tremor (probably related to shallow hydrothermal circulation) was detected by a short-lived seismic array [Hellweg, 1999].

[45] The biggest eruption in the central Andes during the last century occurred at Lascar between 19-20 April 1993, and was the largest at Lascar in over 9000 years [Gardeweg et al., 1998]. That eruption produced $18.5 \mathrm{~km}^{2}$ of pyroclastic flows, an ash cloud that rose $20 \mathrm{~km}$ into the atmosphere, and had a Volcano Explosivity Index (VEI) of 4, with between 1-4 $\times 10^{8} \mathrm{~m}^{3}$ of material ejected [Francis et al., 1993; Smithsonian Institution, 1993b; Gonzalez-Ferran, 1995; Deruelle et al., 1996; Sparks et al., 1997; Wooster and Rothery, 1997; Matthews et al., 1997; Denniss et al., 1998]. We do not see any deformation in two interferograms that span this large eruption (Figure 15). Given the sensitivity of our measurements (about $1-2 \mathrm{~cm}$ ) and a source volume of $1 \times 10^{8} \mathrm{~m}^{3}$, the magma chamber would need to be more than $40 \mathrm{~km}$ deep (below local relief) for this amount of material to be removed and no deformation observed (assuming a spherical source in an elastic halfspace). There is uncertainty in the volume estimate (and therefore the minimum depth) for at least three reasons: (1) the amount of erupted products is uncertain by at least a factor of $4,(2)$ the conversion of the porous erupted volume to dense rock equivalent (DRE) is not precisely known, and (3) the relation between sub-surface volume change and surface deformation depends on the source geometry [Delaney and McTigue, 1994] as well as the rheological structure of the crust.

[46] The trade-off between DRE volume and source depth for a spherical source is shown in Figure 16 assuming 1 or $5 \mathrm{~cm}$ accuracy of the deformation measurements. Realistically, the DRE volume might be as low as $4-5 \times 10^{7} \mathrm{~m}^{3}$, giving a minimum depth of $25-30 \mathrm{~km}$ for a $1 \mathrm{~cm}$ sensitivity to deformation. Even though there is a large region of decorrelation around the edifice in these 

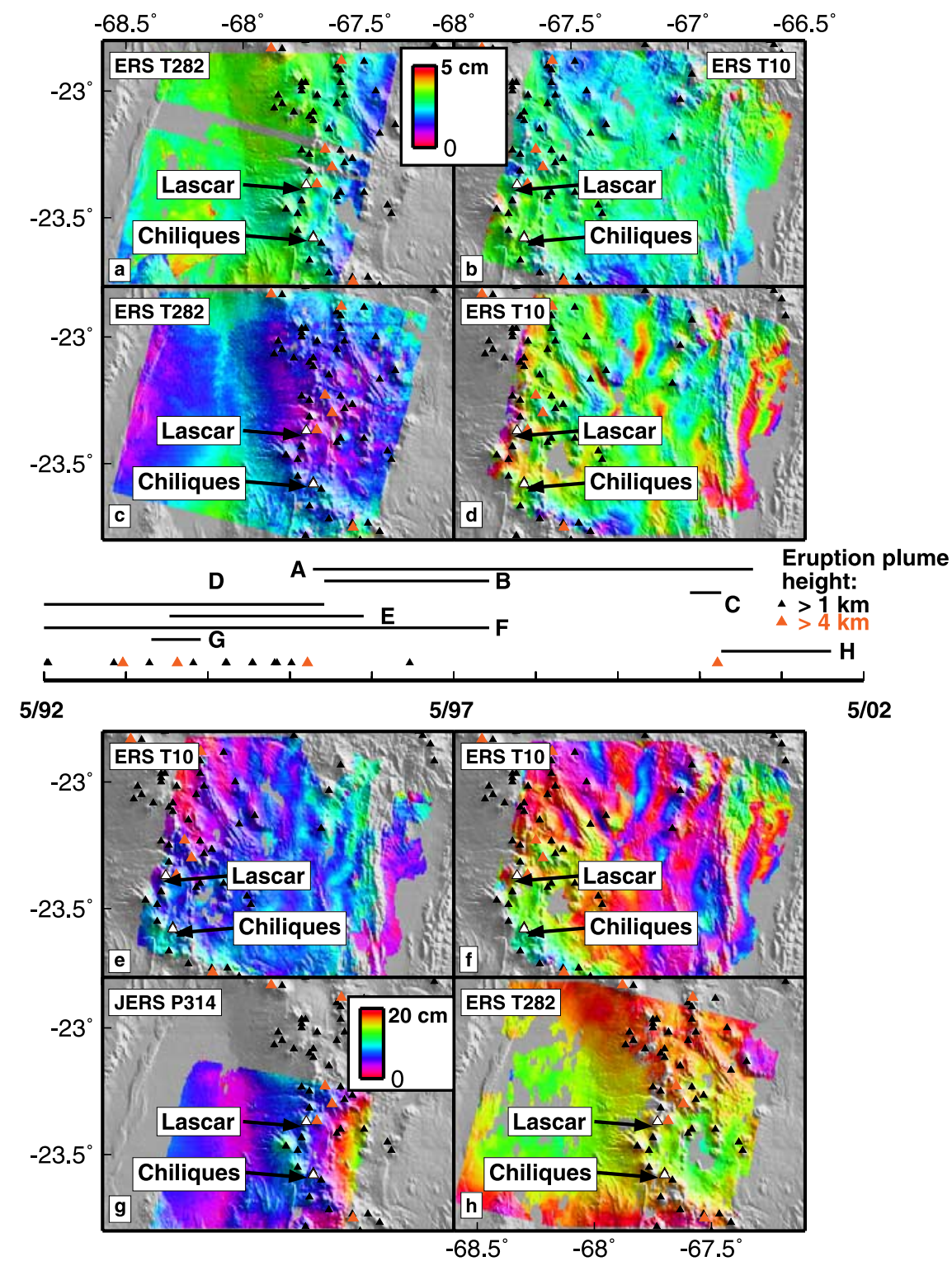

Figure 15. Interferograms showing no deformation at Lascar or Chiliques (both shown as white triangles) from two tracks of radar data from ERS and one path of data from JERS. In the center of the figure, the time period of the interferograms and eruptions of Lascar are shown [Matthews et al., 1997; Smithsonian Institution, 1994a, 1995, 1997a, 1998a, 1998b, 1998c, 2000a]. The height of the eruption cloud above the edifice summit can be used to define the explosivity of the eruption [VEI, Simkin and Siebert, 1994]. There were no eruptions at Chiliques during the time interval, but a thermal anomaly was reported there in early 2002 (see text). Interferograms from ERS orbital track 282 are shown in Figures 15a, 15b, and 15h; from ERS orbital track 10 in Figures 15b, 15d, 15e, and 15f; and JERS path 314 in Figure 15g. Atmospheric artifacts are apparent in most images, and are similar in Figures $15 \mathrm{~d}$ and $15 \mathrm{f}$ which share an identical scene. Atmospheric artifacts are also apparent in the JERS data at the volcanic peaks to the southwest of Lascar, which we do not believe to be deforming. Other symbols are the same as in Figure 1.

interferograms because of the erupted ash, the volume of material removed from the ground is so large that the region of decorrelation does not impact our estimate. Of course some deformation may be hidden within the region of decorrelation (a few $\mathrm{km}$ in diameter), but the volume of material involved must be orders of magnitude smaller than the total erupted volume (Figure 16).

[47] We do not observe any deformation at Lascar in the time interval between May 1992, and December 2001 (Figure 15). This time interval 


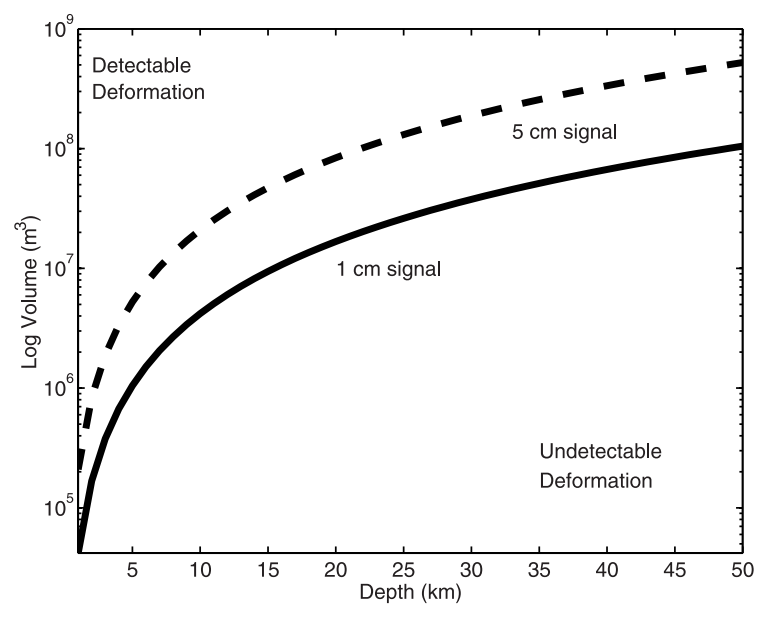

Figure 16. Required volume change at a given depth necessary to produce a maximum surface deformation of 1 and $5 \mathrm{~cm}$. We estimate the accuracy of the ERS measurements to be $1 \mathrm{~cm}$ and the JERS measurements to be $5 \mathrm{~cm}$ (because of the larger atmospheric contamination of these scenes). We assume a constant amplitude signal for detection for sources at all depths, although, in reality, the detection of a deep source is easier than a shallow one because of the larger spatial scale of the deep source should make it easier to differentiate from atmospheric effects.

spans several small eruptions (VEI of 2 or less [Simkin and Siebert, 1994]), with the largest occurring on 20 July 2000, 20 July 1995, and 17 December 1993 [e.g., Smithsonian Institution, 1993d, 1994b, 2000b; Matthews et al., 1997; Wooster and Rothery, 1997; Wooster, 2001]. Even though the eruptions between 11/1993 and 12/2000 are small, we can rule out shallow spherical sources, but can place upper limits on how deep the source is. Assuming appropriate volumes for the largest eruptions during the observed time interval (VEI $2-10^{6}-10^{7} \mathrm{~m}^{3}$, [Simken and Siebert, 1994]) a spherical point source in an elastic half-space must be deeper than 5 and $12 \mathrm{~km}$ (respectively, for the two source strength extremes), given that we could observe surface deformation of $1 \mathrm{~cm}$. The JERS data span a shorter timespan for the 17 December 1993, eruption, but the data seem contaminated by the atmosphere (Figure 15), and the accuracy is superseded by the ERS data [Pritchard, 2003].

[48] It is hard to understand why there is no visible deformation at Lascar, because several lines of evidence suggest shallow activity at Lascar, the rate of outgassing, the size of the collapse craters [Matthews et al., 1997] and the seismic data [Hellweg, 1999]. Furthermore, there must be subsurface magma movement associated with the arrival and removal of material in the several eruptions. Of course, the magma that was erupted could have been emplaced (with accompanying ground deformation) prior to our observations during periods of activity in the 1980s and early 1990s. However, the removal of the material in the eruptions (particularly the $10^{8} \mathrm{~m}^{3}$ removed in April 1993) should have caused surface deformation. For example, subsidence was observed associated with the 1997 eruption of Okmok volcano, Alaska [Mann et al., 2002; Lu et al., 2000c], the 1991 eruption of Westdahl volcano, Alaska [ $L u$ et al., 2003b], and the 1991-1993 Etna, Italy eruptions. At Etna, it is unclear whether the observed subsidence is equal to the volume extruded (for review, see Pritchard [2003]), but in spite of the controversy, all the estimates of the subsidence volume agree with the erupted volume within a factor of 5 or so. However, it should be noted that the Okmok, Westdahl, and Etna lava eruptions might be fundamentally different from the explosive eruptions at Lascar.

[49] We offer three possible explanations for the lack of observed deformation.

[50] 1. As previously mentioned, the source is at least $25 \mathrm{~km}$ deep (or $20 \mathrm{~km}$ below sea level) for the April 1993 eruption. Depending on the DRE of the eruption, a depth of more than $40 \mathrm{~km}$ might be required. Petrological constraints on the depth of the magma chamber for the Soncor eruption of Lascar (26 ka, $8 \mathrm{~km}^{3}$ of material erupted [Gardeweg et al., 1998]) indicate a shallow depth (5-6 km [Matthews et al., 1999]), although earlier work favored a deeper depth (12-22 km, mean $16.6 \mathrm{~km}$ [Matthews et al., 1994]). Petrological depth constraints must be interpreted carefully because magma chambers might exist at multiple levels at a given edifice and the geochemical data might only be sensitive to the final (and shallowest) reservoir. For example, the April 1993 eruption is different from the eruptions in 1986 and 1990 in that its eruptive products are more silicic, indicating the involvement of a more evolved magma [Matthews et al., 1997], and perhaps sup- 
porting the existence of multiple chambers or a single large and heterogeneous chamber. The fact that the large magnitude Soncor eruption did not initiate crater collapse, could indicate the existence of a large, strong, and possibly deep magma chamber [Gardeweg et al., 1998]. The magma chamber at Lascar appears to be in contact with a particular carbonate formation [Matthews et al., 1996]. If the local depth of that formation could be found, there would be an additional constraint on chamber depth. The only seismic constraints on chamber location are a swarm of volcano-tectonic events located at $4.5 \mathrm{~km}$ one week after the April 1993 eruption [Matthews et al., 1997]. It is unclear whether a deep magma chamber ( $>20 \mathrm{~km}$ deep) would be consistent with the shallow lava dome model for the cyclic eruptive pattern at Lascar (see below).

[51] 2. The chamber (or conduit, whatever was holding the magma) behaved rigidly and did not deform when the erupted volumes were removed. This mechanism is proposed for volcanoes that are nearly continuously active (e.g., open-vent systems [Dzurisin, 2003]). While we do not favor this possibility, we note that gravity measurements at several volcanoes (that are more mafic, with less viscous magmas) appear to indicate magma movements without measured surface deformation, possibly as the magma evacuates pore space or moves through a rigid conduit [Rymer et al., 1993; Watanabe et al., 1998; Fernández et al., 2001]. This mechanism will probably not work at Lascar, where viscous magmas are likely coupled to the surrounding rock, and any magma movement should cause deformation.

[52] 3. The absence of observed deformation at Lascar can be understood using a model for the Lascar eruption cycle developed by Matthews et al. [1997]. The April 1993 and other eruptions at Lascar (particularly those on 16 September 1986, 20 February 1990, and 17 December 1993) are believed to be triggered by movements of the surficial lava dome. In the model of Matthews et al. [1997], a lava dome is formed and degasses energetically, but eventually subsides as the magma loses volume. The subsidence as well as loss of magma vesicularity and hydrothermal mineralization reduces the rate of degassing and causes the pressure in the magma chamber to build, eventually leading to eruption. The lava dome has been observed to subside in photographs, and the thermal emission of the fumorales monitored by satellite has been observed to drop before the eruptions in 1986, 1990 and 1993, as expected if the degassing rate decreases [Wooster and Rothery, 1997].

[53] Because of the poor temporal resolution of InSAR, one possible explanation for the observed lack of deformation at Lascar is that the lava dome collapse and pressure build up canceled the pressure release during the eruption, such that there is negligible net deformation. For example, our interferograms spanning the April 1993 eruption begin on 2 May 1992, while satellite observations indicate that dome collapse and pressure build-up began in May-June 1992 [Wooster and Rothery, 1997]. Similarly, our interferograms spanning the December 1993 eruption begin on 13 November 1993, while satellite observations indicate that pressure build up likely began on 12 December 1993. Alternatively, a pressure build-up immediately following the eruption (and concomitant surface inflation) could have nearly canceled the coeruptive pressure decrease and deflation. For example, rapid repressurization (hours-weeks) has been observed in several shallow magma chambers [Dvorak and Dzurisin, 1997; Voight et al., 1999]. Following the 12/17/ 1993 eruption, the cyclic pattern appears to have been broken, perhaps as a result of the 4/1993 eruption changing the plumbing [Wooster and Rothery, 1997; Matthews et al., 1997; Smithsonian Institution, 2000b; Wooster, 2001]. Nonetheless, the $7 / 20 / 2000$ eruption might have followed the previous pattern of pressure build-up before the eruption [Wooster, 2001] such that the InSAR measurements detect little net deformation. This ambiguity in interpretations is directly attributable to the lack of good temporal coverage of the SAR imagery.

\subsubsection{Irruputuncu}

[54] Two eruption plumes were recorded on 1 September 2003 and 26 November 1995 (VEI 2) [Smithsonian Institution, 1997b] at this stratovolcano in Chile. Zebker et al. [2000] made a 

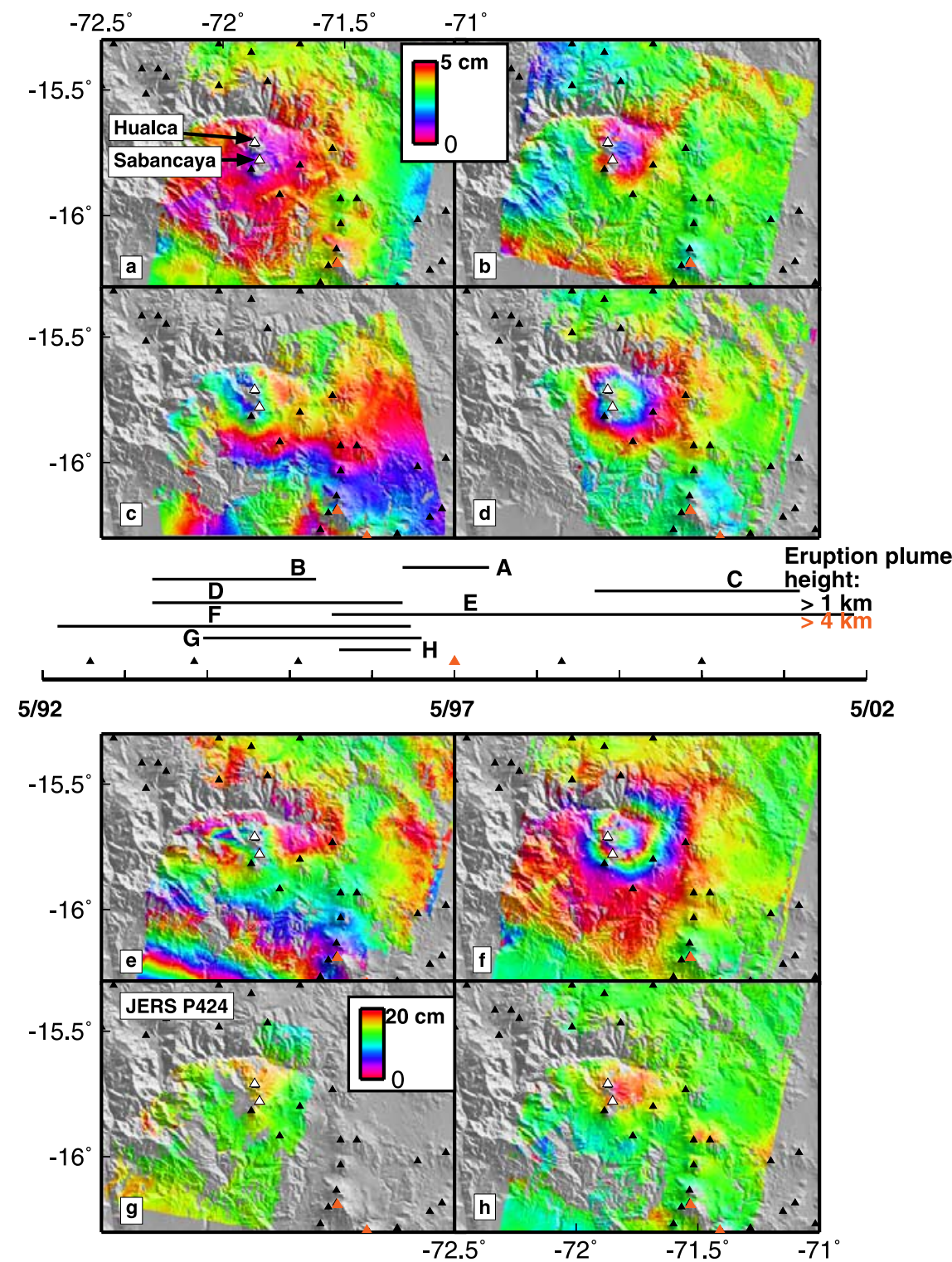

Figure 17. Interferograms spanning eruptive activity at Sabancaya showing deformation at Hualca Hualca (both volcanoes shown as white triangles) from one track of ERS data and one path from JERS. In the center of the figure, the time period of the interferograms and eruptions of Sabancaya are shown [Smithsonian Institution, 1994a, 1995, 1997a, 1998a, 1998b, 1998c, 2000a]. Note that the "eruptions" in August-September, 1998 and April-May, 2000 are represented as discreet events, but are in reality continuing activity. The fringes not related to Hualca Hualca and Sabancaya in c and e are from the 23 June $2001, M_{w} 8.4$ Arequipa earthquake. In these two interferograms, there is no clear signal from the deep magma chamber, although there is clearly a region of localized subsidence to the northwest of Hualca Hualca in Figure 17e (see text). Other symbols are the same as in Figure 1.

70-day interferogram that spanned the $9 / 1$ event, but saw no deformation. We made several interferograms spanning 5/1992-5/1996, and did not observe any deformation at Irruputuncu [see Pritchard, 2003, Appendix]. Assuming the sensitivity to deformation is $1 \mathrm{~cm}$, and magma volumes between $10^{6}-10^{7} \mathrm{~m}^{3}$, the magma chamber would need to be more than $7-15 \mathrm{~km}$ deep
(Figure 16) for eruptions of this size to be undetected.

\subsubsection{Aracar}

[55] An ash plume was observed at this stratovolcano in Argentina on 28 March 1993 (VEI 2) [Smithsonian Institution, 1993a]. No clear deformation signal is observed in several interferograms 
spanning 5/1992-12/2000, although there is clear atmospheric contamination in the single interferogram spanning the eruption (5/1992-10/1997 [see Pritchard, 2003, Appendix]). Assuming the sensitivity to deformation is $3 \mathrm{~cm}$ (because of the larger atmospheric contamination) for this interferogram, and magma volumes between $10^{6}-10^{7} \mathrm{~m}^{3}$, the magma chamber would need to be more than 4$10 \mathrm{~km}$ deep (Figure 16) to explain the lack of deformation.

\subsubsection{Sabancaya}

[56] It is possible that the inflation we see near Hualca Hualca is related to activity at Sabancaya, and local seismic data might provide evidence of a relationship. The eruptions of Sabancaya have been associated with seismic activity and the largest earthquake was a $M_{s} \sim 5$ event on 23 July 1991 [Smithsonian Institution, 1991b]. A seismic array installed in June 1990, found a concentration of earthquakes on the northeast side of Hualca Hualca, about $10 \mathrm{~km}$ from Sabancaya, 4-7 km below sea level. These earthquakes migrated to the south in August and September 1990 [Lazo et al., 1991]. It is possible that the seismic activity in this location is related to the inflation that we observe during later time periods, as they are both in roughly the same location.

[57] Any deformation associated with the eruptions of Sabancaya would be convolved with the deformation NE of Hualca Hualca. Figure 17 shows some of the interferograms at Sabancaya/Hualca Hualca spanning the series of eruptions that followed the renewal of activity at Sabancaya in 1990-1992. There is no unambiguous evidence for deflation of the magma chamber at Hualca Hualca or beneath Sabancaya. There is possibly less than a fringe of subsidence in the interferograms in Figures 17c and 17e, but the effect could be atmospheric. Furthermore, detailed study of these interferograms will not be possible until the effects of the $2001 M_{w} 8.4$ Arequipa earthquake can be properly removed.

[58] There is an east-west elongated pattern of subsidence in the interferogram spanning 11/ 1995-12/2001 (Figure 17e, see Pritchard [2003] for a more detailed look), although the deformation is constrained to have occurred between 2 October 1997 to 10 January 1999 or 9 July 2001 to 21 December 2001. This subsidence does not appear related to the magma chamber deformation imaged in the other interferograms, and might be related to hydrologic activity. The largest eruption during the time period for which data are available was in May 1995 and had a VEI of 3 (between $10^{7}$ and $10^{8} \mathrm{~m}^{3}$ ). If the magma chamber was more than $15 \mathrm{~km}$ below the surface, the deformation signal might be below the $1 \mathrm{~cm}$ threshold (Figure 16). Our modeling suggests that the chamber is 13$23 \mathrm{~km}$ deep below Hualca Hualca, suggesting that the subsidence might not be observed if the origin of the eruptions came from the modeled source, and the erupted volume is near the low end of the possible range. The rate of inflation does not seem to be directly affected by the eruption, although the temporal resolution is poor. While not temporally well constrained, inflation of Hualca Hualca seems to have stopped in 1997 (Figure 17), perhaps related to the large eruption in May 1997. Sabancaya has continued to emit gas, but no large eruptions have been reported since the cessation of inflation at Hualca Hualca.

\section{Magmatic Additions to a Volcanic Arc}

[59] Constraining the rate of magmatic additions to the crust is important for understanding the evolution of mountain belts and continents. For example, the rate of volcanic output (and implied rate of intrusion) is incapable of explaining the crustal thickening of the central Andes during the past $10 \mathrm{Ma}$, so that another process (tectonic shortening) must be more important [Allmendinger et al., 1998]. Converting volcanic output to crustal growth is difficult because several important parameters are poorly constrained. For example, while determining the rate of volcanic output is logically straight forward (by accounting for the volumes and ages of subaerial eruptive products), in practice, even the volumes of recent eruptions are only known to an order of magnitude or so. To convert volcanic output to crustal addition, the ratio of intrusive to extrusive eruptive products $\left(R_{I / E}\right)$ is required, but is crudely 
constrained by geologic observations [Francis and Hawesworth, 1994]. Our survey of deformation and presumed magma movements within the central Andean arc over the course of a decade can provide an observational constraint on the current $R_{I / E}$.

[60] Our estimates of intruded volumes are lower limits, because magma intrusions might not manifest themselves as detectable surface deformation, particularly if the injection is deep and/or the volume change is small (Figure 16). Our volume estimates are also a lower limit because magma movements might not cause surface deformation if the conduit behaves rigidly or magma fills void space. We assume that surface inflation is entirely due to magma injection, and not from hydrothermal processes or an increase in gas pressure within the magma chamber. While neglecting these other processes might overestimate the volume of magma intruded, the fact that we also neglect magma compressibility, which can accommodate some of the intruded magma without causing surface deformation [Johnson et al., 2000] will serve to underestimate the intruded volume. It is difficult to know how these different processes will trade off, so we make the simplifying assumption that all intruding magma (and only magma) causes surface deformation. For this reason, we neglect the subsidence of Cerro Blanco caldera, which is likely due to cooling/crystallization from a previous injection coupled with hydrothermal activity. We assume that our survey is complete enough (91\% of the 390 volcanic edifices thought to have been active in the last 1-2 Ma) to allow for a lower limit upon the annual rate of crustal deformation and inferred magmatic intrusion.

[61] Given all of these assumptions, the lower bound of the volume of magma intruded in the central Andean arc is $4-6 \times 10^{-2} \mathrm{~km}^{3} / \mathrm{yr}$ for spherically shaped intrusions or $2.6-5 \times 10^{-5}$ $\mathrm{km}^{3} / \mathrm{yr}$ per $\mathrm{km}$ of arc length. Over a similar timespan (1990-2000), between about 0.9-4.6 $\times 10^{-5}$ $\mathrm{km}^{3} / \mathrm{yr} / \mathrm{km}$ of material was erupted in the central Andes. This range in values corresponds to eruptions in the Smithsonian database [Globalism volcanism report available at http://www.volcano. si.edu/; Simkin and Siebert, 1994], with additional volume constraints for large eruptions [Thouret et al., 1995; Deruelle et al., 1996; Smithsonian Institution, 1994c]. Because all of the eruptions were explosive, the actual dense rock equivalent volume of this material is less, perhaps by a factor of $2-3$, meaning that $R_{I / E}$ is between $1-10$. It should be remembered that this calculation only considers the measured input and output of the arc over about a 10 year period. The mass that was intruded during an earlier time and extruded in eruptions at Lascar (and elsewhere) is not considered, nor is volume of material intruded during this time interval that might be extruded in the future. Previous calculations of $R_{I / E}$ from the central Andes were made by comparing the volume of volcanic rocks to batholithic rocks [Francis and Rundle, 1976] or estimating the amount of fractional crystallization [Francis and Hawesworth, 1994] are also between 1-10, with the low values corresponding to andesitic melts and the higher values to more silicic melts [Francis and Hawesworth, 1994]. Values of $R_{I / E}$ between 1-10 have also been reported in many other arcs [e.g., Crisp, 1984].

[62] Volcanic eruptions in the central Andes are strongly episodic, and so we need to consider whether a decade of observations is sufficient to characterize the long-term rate of volcanic input and output. For example, large eruptions are volumetrically the most important [Pyle, 1995]. The largest historic eruption in the central Andes was in 1600 [Thouret et al., 2002; Adams et al., 2001]. Although time averaging effects might exist, the rate of volcanic output averaged over different timescales $\left(10-10^{7}\right.$ years) is consistent within an order of magnitude, which is within the uncertainty of the individual estimates [Pritchard, 2003]. It is more difficult to estimate rates of magmatic intrusion over different timescales, particularly because the subsurface shape and age of batholiths are poorly known and it is difficult to determine erosion rates. Our values of $2.6-5 \times 10^{-5} \mathrm{~km}^{3}$ / $\mathrm{yr} / \mathrm{km}$ are within an order of magnitude of geologic averages of $0.3-2.6 \times 10^{-5} \mathrm{~km}^{3} / \mathrm{yr} / \mathrm{km}$ for the coastal batholith of Peru used as an analog for the current central Andean arc [Francis and Rundle, 1976]. Therefore given all of the uncertainties 
involved, our 10 year study of magma intrusions and extrusions is consistent with the geologic rates. Many workers have used the rate of magmatic addition to constrain the rate of continental crustal growth, but this is a difficult extrapolation [e.g., Pritchard, 2003].

\section{Physical Cause of Deformation}

[63] The cause of deformation at the four volcanoes is ambiguous, although some constraints can be made. Because hydrothermal systems are usually less than $10 \mathrm{~km}$ deep, the $>16 \mathrm{~km}$ source depth for deformation at Uturuncu suggests a magmatic origin. The Uturuncu source may be related to a region of low seismic velocity and inferred partial melt [Chmielowski et al., 1999], part of the Altiplano-Puna Magmatic Complex [de Silva, 1989]. The dimensions of the partially molten region are well constrained by several seismic arrays in the area, but the inferred depth and thickness of the magma body are model dependent and particularly sensitive to how the strong anisotropy above the magma body is modeled [Leidig and Zandt, 2003]. Plausible depths to the magma body are between 14-17 km below local relief [Zandt et al., 2003]. Support for the existence of partial melt in this area also comes from seismic attenuation studies [Haberland and Rietbrock, 2001] and electromagnetic experiments [Schilling et al., 1997]. Lazufre and Cerro Blanco lie near regions with low seismic velocities, but more than $200 \mathrm{~km}$ from the lowest velocities [Yuan et al., 2000; Zandt et al., 2003]. The fact that the deformation rate changes abruptly over a timescale of a year or less at Uturuncu, Hualca Hualca, and Lazufre is consistent with the migration of magmatic material. If the deformation was caused only by diffusion of heat (through heating or melting), we would not expect the rate of deformation to change so abruptly. Subsidence at Cerro Blanco is considered in the next section.

\subsection{Subsidence}

[64] Several mechanisms have been proposed for subsidence at calderas: cooling and solidification of magma, regional extension, and removal of hydrothermal or magmatic fluids with concomitant compaction [e.g., Newhall and Dzurisin, 1988].
Without knowing the history of uplift and subsidence at Cerro Blanco or the characteristics (or existence) of its hydrothermal or magmatic system, it is difficult to constrain the source of the subsidence. However, tectonic extension and magma withdrawal are unlikely explanations for the subsidence at Cerro Blanco. The existence and magnitude of regional extension that might be localized by weakening effects of a magma body (as proposed for Yellowstone and Medicine Lake [Dvorak and Dzurisin, 1997]) is unknown. Magma withdrawal was probably not horizontal because we do not see any nearby areas of inflation (such as seen at Aira and Sakurajima, Japan [Tada and Hashimoto, 1989]), although if such movement was diffuse it would be hard to detect. Here we outline some simple physical arguments suggesting that conductive cooling and crystallization of a magma chamber alone can not explain the rate of subsidence at Cerro Blanco, and thus we posit the existence of a hydrothermal system to increase the cooling rate and/or to cause subsidence through poroelastic effects.

[65] Magma cooling and solidification both involve contraction which can lead to surface subsidence. Conductive cooling is an inefficient process, especially because as cooling progresses, the immediate surrounding material warms up and the rate of heat loss diminishes. To see if conductive cooling alone can explain the observations, we have done simple numerical simulations of onedimensional spherical conductive cooling (accounting for phase changes) using a finite difference method (see Toksöz and Solomon [1973] for the equations used), as well as orderof-magnitude calculations [Pritchard, 2003].

[66] There are at least three different scenarios for conductive heat loss with different consequences for the rate of cooling and volume change. The most efficient heat loss configuration is if the magma chamber is fluid, convecting and isothermal, and conducts heat into the surrounding medium [Marsh, 1989]. Heat loss from the isothermal magma chamber can be twice as great as from a nonconvecting magma chamber [Marsh and Maxey, 1985]. As the magma chamber starts to crystallize, its viscosity increases and convection 
becomes less vigorous, but for the timescales and magma volumes we are interested in, the amount of crystallization is small. The other two scenarios are a nonconvective, liquid magma chamber and a nonconvective solid magma chamber, and have different amounts of volume change per unit cooling. We have tested all three scenarios for conductive cooling, and found that a chamber radius of more than $17 \mathrm{~km}$ would be required to achieve the observationally required volume. Such a large radius requires at least an equal depth for the source, and is not consistent with our observations of a source depth between 9-14 km. Of course, the surface deformation pattern is affected by the finite size of the magma chamber, but when we do inversions accounting for this effect (using the corrections of McTigue, 1987), we still find a source depth of $11 \mathrm{~km}$. Furthermore, a chamber $17 \mathrm{~km}$ in radius is probably implausibly big (for example, it would have 20 times the volume of the inferred magma chamber in Long Valley caldera, California [McTigue, 1987]).

[67] Cooling and/or crystallization of a magma chamber by conductive processes alone is therefore unlikely to be the cause of the observed deformation, and a hydrothermal system must exist. This is not surprising, since at other calderas, the removal of fluids is the favored cause of subsidence (e.g., Yellowstone and Campi Flegrei [Dvorak and Mastrolorenzo, 1991; Dvorak and Dzurisin, 1997; Dzurisin et al., 1999]), although all these authors acknowledge that there the exact cause of the deformation is uncertain. Fluids (gas and brine) exsolved from the cooling magma body could be removed allowing compaction and subsidence of the previously fluid-filled pores [Dvorak and Mastrolorenzo, 1991]. Alternatively, or concurrently, a hydrothermal system could become self-sealed and pressurized by the fluids causing inflation, or subsidence when the seal is broken [Dzurisin et al., 1999]. The inferred depth of activity at Cerro Blanco $(9-14 \mathrm{~km})$ is similar to that at Yellowstone $(8.5 \pm 4 \mathrm{~km}$ [Wicks et al., 1998]) but deeper than at Campi Flegrei (3 km [e.g., Dvorak and Dzurisin, 1991]). Ultimately, discriminating between hydrothermal and magmatic activity as the principle cause of subsidence requires repeated microgravity observations to constrain the density [Berrino et al., 1992; Battaglia et al., 1999], but studies of the history of uplift and/or eruptions at Cerro Blanco and confirmation of the existence of a hydrothermal system are also needed.

\subsection{Magmatic Dipoles}

[68] If deformation is caused by migration of mass, the sources are in fact dipoles, not monopoles. While we have used surface deformation data to constrain the location of the inflation source, if the inflation is caused by magma injection, there must also be a source of deflation affecting the surface deformation. Of course, it is possible that the inflation we infer is not the result of magma movement. If the sources of inflation and deflation (the dipole) are close together and nearly the same shape, the surface deformation pattern can be strongly affected, such that the inferred source depth and volume change will be inaccurate. For the interferograms of Hualca Hualca and Uturuncu, we infer about $10^{8} \mathrm{~m}^{3}$ of magma to be moving at depth, and if all of this material is removed from a spherical chamber, the effects of this removal should be observable if the chamber is less than about $40 \mathrm{~km}$ deep (Figure 16). Our preliminary tests of the dipole effect for Hualca Hualca, Lazufre, and Uturuncu indicate that the most important implication is that we might have underestimated the volume of magma that moved. The dipole effect would be reduced if the source of deflation was broad and diffuse, i.e., the magma was collected from a large reservoir or series of channels. A better understanding of the magma plumbing system from seismic tomography and geochemistry is needed to asses the importance of the dipole effect.

\section{Conclusions}

\subsection{What is an Active Volcano?}

[69] Over the 5-10 years for which data are available, we can detect deformation at only 4 of the almost 900 edifices surveyed, although more subtle deformation might also be occurring below our detection threshold. Such results would 
involve months to years to accomplish if we were confined to ground measurements. Furthermore, ground surveys might not have detected the volcanic sources because they were not listed as "potentially active" volcanoes or the nonvolcanic deformation since such deformation was not predicted.

[70] Clearly, at silicic stratovolcanoes, like those in the central Andes, there are different definitions of "active": those with eruptions in the last 10,000 years (44 volcanoes [de Silva and Francis, 1991]), fumarolically active (15 volcanoes), centers with a measurable thermal anomaly ( 2 volcanoes), actively deforming (4 volcanoes), and actively erupting (4 volcanoes in the 1990's). Another criterion, seismically active, can not be applied in the central Andes because of the lack of data. This and other InSAR surveys [Lu et al., 2002a; Wicks et al., 2002; Lu et al., 2000d; Amelung et al., 2000] indicate that the different definitions of activity do not completely overlap. Moreover, the manifestations of activity (fumaroles, thermal anomalies, and deformation) are temporally variable, so that all "potentially active" volcanoes need to be monitored regularly for temporary bursts of activity. For example, only two of the four centers of deformation were active during the entire time period, and even the deformation at these centers (Uturuncu and Cerro Blanco) appears time-dependent. We also find that the thermal anomaly at Chiliques was transient (less than 18 months).

[71] While the time-dependent variations in deformation at the four volcanoes might represent normal intrinsic fluctuations, some of the changes could be related to external processes. The changes in activity at Uturuncu and Lazufre could represent the influence of a $M_{w} 7.1$ subduction zone earthquake in 1998. Such remote triggering of deformation in volcanic areas has been observed before, and a variety of mechanisms might be involved [e.g., Barrientos, 1994; Johnston et al., 1995; Brodsky, 2001]. Inflation at Hualca Hualca stopped in 1997, perhaps related to a large eruption of nearby Sabancaya volcano in May, 1997, although there is no obvious relation between the rate of deformation and the eruptions of Sabancaya. We indirectly infer subsidence between late 1997 and early 1999, to account for the fact that inflation (albeit barely above the detection threshold) seems to be in interferograms spanning 1995-1997, but not in interferograms spanning 1995-2001 (Figures 9 and 10).

[72] The low number of deforming volcanoes in the central Andes relative to the total number surveyed should not be considered representative of all volcanic arcs in the world. For example, the Alaskan/Aleutian arc has about the same number of volcanoes in the Smithsonian database as the central Andes (about 80), but many more historic eruptions (41 compared to 17 [Miller et al., 1998; Simkin and Siebert, 1994; Smithsonian Institution, Global volcanism report, available at http://www. volcano.si.edu/, 2003]) and more actively deforming (9 compared to 4 [Lu et al., 1997, 2000a, 2000c, 2000b, 2002a, 2002c, 2002b, 2003a; Price, 2002; Mann and Freymueller, 2003]). The lower level of activity in the central Andes might be related to the fact that magma has a longer journey through the crust in the Andes (the crust is 50$70 \mathrm{~km}$ thick), or the composition of the lavas (there are more large mafic volcanoes in Alaska) [Miller et al., 1998; Simkin and Siebert, 1994; Global volcanism report]. The level of activity in the central Andes is more comparable with the other active Andean chains, the northern Andes $\left(6^{\circ} \mathrm{N}-\right.$ $\left.2^{\circ} \mathrm{S}\right)$ and the southern Andes $\left(33-50^{\circ} \mathrm{S}\right)$. The number of historic eruptions in the central Andes (17) is similar to the number in the northern Andes (15), although less than the southern Andes (29) [Simkin and Siebert, 1994; Global volcanism report]. The number of eruptions between 19902000 is about the same in the central (4), northern (5) and southern (6) Andes, and lower than the number in Alaska/Aleutians (17) (Global volcanism report).

\subsection{Erupting Volcanoes Without Deformation}

[73] The lack of deformation at Lascar (particularly the lack of subsidence associated with the eruptions) is mysterious, but has the potential to provide insight into the plumbing of this volcano. A deep magma chamber would explain the lack of deformation, but it must be at least $25 \mathrm{~km}$ (possibly 
much deeper) to explain the lack of deformation from the April 1993 eruption. Such a deep magma chamber might not be consistent with the fact that shallow movements of the lava dome seem to trigger eruptions in at least 1986-1993 [Matthews et al., 1997]. Considering the long periods between observations, inflation and deflation could nearly exactly cancel each other, especially if the eruptive process is cyclic or the magma chamber quickly repressurizes.

[74] We did not observe subsidence associated with eruptions at Irruputuncu, Aracar, or Sabancaya, but these eruptions were smaller than those at Lascar, and so could plausibly be hidden by magma chambers as shallow as $10 \mathrm{~km}$ below the surface. In the case of Sabancaya, subsidence could have been masked by inflation from the magma chamber near Hualca Hualca, or the eruptions might have been directly fed by this chamber. Other recent studies indicate many eruptions (smaller than the April, 1993 Lascar eruption) with no observed co-eruptive or posteruptive subsidence: Shishaldin, Alaska, VEI 3 [Lu et al., 2000d]; Makushin, Alaska, VEI 1 [Lu et al., 2002c]; Pavlof, Alaska, VEI 2 [Lu et al., 2003a]; Clevland, Alaska, VEI 3 [Lu et al., 2003a]; Korovin, Alaska, VEI 3 [ $L u$ et al., 2003a]; Sakurajima, Japan, VEI 2 during the observation period [Zebker et al., 2000]; Fogo, Cape Verde Islands, VEI 2, but erupted $10^{7} \mathrm{~m}^{3}$ of lava [Amelung and Day, 2002]; Piton de la Fournaise, Reunion, VEI 1 , but erupted $10^{7} \mathrm{~m}^{3}$ of lava [Sigmundsson et al., 1999]. In the case of Fogo and Piton de la Fournaise, the lack of deformation was used to constrain the minimum magma chamber depth, and was supported by ancillary geophysical or geochemical data.

\subsection{Location of Reservoirs}

[75] A principle goal of this survey of volcanic activity was to determine the depths of magma chambers at several volcanic edifices, in order to understand whether magma plumbing is the same at different centers within an arc. Our experiments with different elastic media, the trade-off between source depth and strength, and different source geometries indicate that our observed volcanic deformation could be due to magma activity within a range of depths, but that this range is usually less than $10 \mathrm{~km}$. From north to south, the inferred source depths (below sea level) are: $8-18 \mathrm{~km}$ at Hualca Hualca; $12-25 \mathrm{~km}$ for Uturuncu; 5-13 km for the Lazufre, and 5-10 km at Cerro Blanco (Table 3). The depth of microseismicity could be used as an independent check on source depth. As mentioned above, earthquakes detected in 1990 near Sabancaya might be related to the source of deformation at Hualca Hualca. It is less likely that shallow seismicity at Uturuncu detected in April 2003 [Smithsonian Institution, 2003] is related to the magma body.

[76] The maximum source depths at Uturuncu and Hualca Hualca are among the deepest ever determined using geodetic data. Prior to the late 1990s, only calderas had reliable source depths greater than $6 \mathrm{~km}$ (Medicine Lake, Yellowstone, and Long Valley, USA; Aira and Sakurajima, Japan [Dvorak and Dzurisin, 1997]). The deepest sources inferred from deformation observed with geodetic data from other arcs are as follows: $9 \mathrm{~km}$ Westdahl, Aleutians [Lu et al., 2000d]; $6.5 \mathrm{~km}$ South Sister, Cascades [Wicks et al., 2002]; $7.9 \mathrm{~km}$ Mount Iwate, Japan [Nishimura et al., 2001]; $7 \mathrm{~km}$ Hengill, Iceland [Feigl et al., 2000]; $5 \mathrm{~km}$ Cerro Azul, Galapagos [Amelung et al., 2000]; $8.5 \mathrm{~km}$ Merapi, Indonesia [Beauducel and Cornet, 1999]; 6-16 km Mt. Etna, Italy. The lack of deformation associated with eruptions has also been used to constrain chamber depths, although explanations other than a deep chamber are possible (see above): $>16.5$ km Fogo, Cape Verde [Amelung and Day, 2002]; $>7$ km Piton de la Fournaise, Reunion [Sigmundsson et al., 1999]. The deeper source depths in the central Andes might be related to the thicker crust $(50-70 \mathrm{~km})$, in this arc relative to the other arcs.

[77] Three of the four centers of deformation found in this survey are offset from the eruptive vent on the volcanic edifice. The offset is model dependent (Table 3), but is about: $5 \mathrm{~km}$ at Uturuncu, Bolivia; $7-10 \mathrm{~km}$ at Lazufre (the smaller value is appropriate if the chamber feeds Cordon del Azufre and the larger number is favored if the chamber feeds 
Lastarria); and 3-8 $\mathrm{km}$ at Hualca Hualca (where the smaller number represents the distance between Hualca Hualca and the chamber and the larger number is the distance to the more active Sabancaya). A horizontal offset between the source of deformation and an eruptive vent is seen in many locations: about $2 \mathrm{~km}$ at Mt. Peulik, Alaska [Lu et al., 2002a]; $5 \mathrm{~km}$ at South Sister, Oregon [Wicks et al., 2002], and Makushin, Alaska [Lu et al., 2002c]; and $13 \mathrm{~km}$ at Mt. Iwate, Japan [Nishimura et al., 2001]. Several eruptions seem to have been fed by magma chambers 5-10 km away from the eruptive center at Novarupta, Alaska in 1912 [Curtis, 1968], and at Okmok, Alaska in 1997 [Lu et al., 2000d]. As mentioned above, the magma chamber near Hualca Hualca might have fed eruptions at nearby Sabancaya. Recent modeling indicates that a magma chamber offset from the edifice can still feed eruptions on the edifice, because dikes from the distant magma chamber are focused by the local topographic stresses toward the edifice [Muller et al., 2001]. However, the reason that the intrusion occurs in a magma chamber offset from the central edifice is unknown: is this a location favored by the local stress field, by the process of melt migration from deeper levels, or is it just random where an intrusion will occur?

\section{Acknowledgment}

[78] This study used ERS SAR imagery acquired under a Category 1 research project from the European Space Agency. We thank R. Lohman, Y. Fialko, and L. Rivera for modeling software, S. de Silva for an electronic version of his volcano database, and D. Stevenson, M. Gurnis, S. Sparks, J. Naranjo, J. Clavero and M. Abrams for useful discussions. We thank Nicki Stevens and Falk Amelung for critical reviews and comments by associate editor John Beaven. JERS data was provided by the Remote Sensing Technology Center of Japan through research users A. Tanaka and P. Rosen. SRTM DEMs were supplied courtesy of NASA. The GMT program was used to create several figures [Wessel and Smith, 1998]. M.E.P. was partly supported by a NASA Earth System Science fellowship. Contribution number 9029 of the Division of Geological and Planetary Science, Seismological Laboratory, California Institute of Technology.

\section{References}

Adams, N. K., S. L. deSilva, S. Seld, G. Salas, S. Schubring, J. L. Permenter, and K. Arbesman (2001), The physical volcanology of the 1600 eruption of Huaynaputina, southern Peru, Bull. Volcanol., 62, 493-518.

Allmendinger, R. W., T. E. Jordan, S. M. Kay, and B. L. Isacks (1998), The evolution of the Altiplano-Puna plateau of the central Andes, Ann. Rev. Earth Planet Sci., 25, 139-174.

Amelung, F., and S. Day (2002), InSAR observations of the 1995 Fogo, Cape Verde, eruption: Implications for the effects of collapse events upon island volcanoes, Geophys. Res. Lett., 29(12), 1606, doi:10.1029/2001GL013760.

Amelung, F., S. Jónsson, H. Zebker, and P. Segall (2000), Widespread uplift and 'trapdoor' faulting on Galápagos volcanoes observed with radar interferometry, Nature, 407, 993-996.

Baker, M. C. W., and P. W. Francis (1978), Upper Cenozoic volcanism in the central Andes - Ages and volumes, Earth Planet. Sci. Lett., 41, 175-187.

Barrientos, S. (1994), Large thrust earthquakes and volcanic eruptions, Pure Appl. Geophys., 142, 225-237.

Battaglia, M., C. Roberts, and P. Segall (1999), Magma intrusion beneath Long Valley caldera confirmed by temporal changes in gravity, Science, 285, 2119-2122.

Beauducel, F., and F.-H. Cornet (1999), Collection and threedimensional modeling of GPS and tilt data at Merapi volcano, Java, J. Geophys. Res., 104, 725-736.

Beauducel, B., P. Briole, and J.-L. Foger (2000), Volcano-wide fringes in ERS synthetic aperture radar interferograms of Etna (1992-1998): Deformation or tropospheric effect?, J. Geophys. Res., 105, 16,391-16,402.

Berrino, G., H. Rymer, G. C. Brown, and G. Corrado (1992), Gravity height correlations for unrest at calderas, J. Volcanol. Geotherm. Res., 53, 11-26.

Brodsky, E. E. (2001), Studies in fluid dynamics as applied to seismology and volcanology, Ph.D. thesis, California Institute of Technology, Pasadena, Calif.

Cattin, R., P. Briole, H. Lyon-Caen, P. Bernard, and P. Pinettes (1999), Effects of superficial layers on cosesimic displacements for a dip-slip fault and geophysical implications, Geophys. J. Int., 137, 149-158.

Cayol, V., and F. H. Cornet (1998), Effects of topography on the interpretation of the deformation field of prominent volcanoes: Application to Etna, Geophys. Res. Lett., 25, 1979-1982.

Cervelli, P., M. H. Murray, P. Segall, Y. Aoki, and T. Kato (2001), Estimating source parameters from deformation data, with an application to the March 1997 earthquake swarm off the Izu Peninsula, Japan, J. Geophys. Res., 106, 11,21711,237.

Chmielowski, J., G. Zandt, and C. Haberland (1999), The central Andean Altiplano-Puna Magma Body, Geophys. Res. Lett., 26, 783-786.

Chorowicz, J., B. Deffontaines, D. Huamanrodrigo, R. Guillande, F. Leguern, and J. C. Thouret (1992), SPOT satellite monitoring of the eruption of Nevado Sabancaya Volcano (southern Peru), Remote Sens. Environ., 42, 43-49.

Crisp, J. A. (1984), Rates of magma emplacement and volcanic output, J. Volc. Geotherm. Res., 20, 177-211.

Curtis, G. H. (1968), The stratigraphy of the ejecta of the 1912 eruption of Mount Katmai and Novarupta, Alaska, in Studies 
in Volcanology, a Memoir in Honor of Howell Williams, edited by R. R. Coats, R. L. Hay, and C. A. Anderson, Mem. Geol. Soc. Am., 116, 153-210.

Davis, P. M. (1986), Surface deformation due to inflation of an arbitrarily oriented triaxial ellipsoidal cavity in an elastic half-space, with reference to Kilauea Volcano, Hawaii, J. Geophys. Res., 91, 7429-7438.

Delaney, P. T., and D. F. McTigue (1994), Volume of magma accumulation or withdrawal estimated from surface uplift or subsidence, with application to the 1960 collapse of Kilauea volcano, Bull. Volcanol., 56, 417-424.

Denniss, A. M., A. J. L. Harris, D. A. Rothery, P. W. Francis, and R. W. Carlton (1998), Satellite observations of the April 1993 eruption of Lascar volcano, Int. J. Remote Sens., 19, 801-821.

Deruelle, B., O. Figueroa, E. Medina, J. Viramonte, and M. Maragano (1996), Petrology of pumices of April 1993 eruption of Lascar (Atacama, Chile), Terra Nova, 8, 191-199.

de Silva, S. L. (1989), Altiplano-Puna volcanic complex of the central Andes, Geology, 17, 1102-1106.

de Silva, S. L., and P. W. Francis (1991), Volcanoes of the Central Andes, Springer-Verlag, New York.

Dieterich, J., and R. Decker (1975), Finite element modeling of surface deformation associated with volcanism, J. Geophys. Res., 80, 4094-4102.

Dixon, J. P., S. Stihler, J. Power, G. Tytgat, S. Estes, S. Moran, J. Paskievitch, and S. McNutt (2002), Catalog of earthquake hypocenters at Alaskan volcanoes: January 1, 2000 through December 31, 2001, U. S. Geol. Surv. Open File Rep., 02342, 56 pp.

Du, Y., P. Segall, and H. Gao (1997), Quasi-static dislocations in three dimensional inhomogeneous media, Geophys. Res. Lett., 24, 2347-2350.

Dvorak, J. J., and D. Dzurisin (1997), Volcano geodesy: The search for magma reservoirs and the formation of eruptive vents, Rev. Geophys., 35, 343-384.

Dvorak, J. J., and G. Mastrolorenzo (1991), The mechanisms of recent vertical crustal movements in Campi Flegrei caldera, southern Italy, Spec. Pap. Geol. Soc., 263, 47 pp.

Dzurisin, D. (2003), A comprehensive approach to monitoring volcano deformation as a window on the eruption cycle, Rev. Geophys., 41(1), 1001, doi:10.1029/2001RG000107.

Dzurisin, D., C. Wicks Jr., and W. Thatcher (1999), Renewed uplift at Yellowstone caldera measured by leveling surveys and satellite radar interferometry, Bull. Volcanol., 61, 349355.

Emardson, T. R., M. Simons, and F. H. Webb (2003), Neutral atmospheric delay in interferometric synthetic aperture radar applications: Statistical description and mitigation, J. Geophys. Res., 108(B5), 2231, doi:10.1029/2002JB001781.

Feigl, K. L., J. Gasperi, F. Sigmundsson, and A. Rigo (2000), Crustal deformation near Hengill volcano, Iceland 19931998: Coupling between magmatic activity and faulting inferred from elastic modeling of satellite radar interferograms, J. Geophys. Res., 105, 25,655-25,670.

Feigl, K. L., F. Sarti, H. Vadon, S. McClusky, S. Ergintav, P. Durand, R. Burgmann, A. Rigo, D. Massonnet, and R. J. Reilinger (2002), Estimating slip distribution for the Izmit mainshock from coseismic GPS, ERS-1, RADARSAT, and SPOT measurements, Bull. Seismol. Soc. Am., 92, 138 160.

Fernández, A., P. K. Hörmann, S. Kussmaul, J. Meave, H. Pilcher, and T. Subieta (1973), First petrologic data on young volcanic rocks of SW-Bolivia, Tschermaks. Mineral. Petrogr. Mitt., 19, 149-172.

Fernández, J., K. F. Tiampo, G. Jentzsch, M. Charco, and J. B. Rundle (2001), Inflation or deflation? New results for Mayon volcano applying elastic-gravitational modeling, Geophys. Res. Lett., 28, 2349-2352.

Fialko, Y., Y. Khazan, and M. Simons (2001a), Deformation due to a pressurized horizontal circular crack in an elastic half-space, with applications to volcano geodesy, Geophys. J. Int., 146, 181-190.

Fialko, Y., M. Simons, and D. Agnew (2001b), The complete (3-D) surface displacement field in the epicentral area of the $1999 M_{w} 7.1$ Hector Mine earthquake, California, from space geodetic observations, Geophys. Res. Lett., 28, 3063-3066.

Francis, P. W., and C. J. Hawesworth (1994), Late Cenozoic rates of magmatic activity in the central Andes and their relationships to continental crust formation and thickening, J. Geol. Soc. London, 151, 845-854.

Francis, P. W., and C. C. Rundle (1976), Rates of production of the main Andean magma types, Geol. Soc. Am. Bull., 87, 474-480.

Francis, P. W., S. Self, C. M. Oppenheimer, and D. A. Rothery (1993), The April 1993 eruption of Lascar, north Chile, observations and inferences (abstract), Eos Trans. AGU, 74,651 .

Gardeweg, M. C., R. S. J. Sparks, and S. J. Matthews (1998), Evolution of Lascar volcano, northern Chile, J. Geol. Soc. London, 155, 89-104.

Gonzalez-Ferran, O. (1995), Volcanes de Chile (in Spanish), Instituto Geografico Militar, Santiago, Chile.

Graeber, F. M., and G. Asch (1999), Three-dimensional models of $P$ wave velocity and $P$-to- $S$ velocity ratio in the southern central Andes by simultaneous inversion of local earthquake data, J. Geophys. Res., 104, 20,237-20,256.

Haberland, C., and A. Rietbrock (2001), Attenuation tomography in the western central Andes: A detailed insight into the structure of a magmatic arc, J. Geophys. Res., 106, 11,15111,167 .

Hanssen, R. A. (2001), Radar Interferometry: Data Interpretation and Error Analysis, Kluwer Acad., Norwell, Mass.

Hellweg, M. (1999), Listening carefully: Unique observations of harmonic tremor at Lascar volcano, Chile, Ann. Geofis., $42,451-464$.

Hoffmann, J. (2003), The application of satellite radar interferometry to the study of land subsidence over developed aquifer systems, Ph.D. thesis, Stanford Univ., Stanford, Calif.

Johnson, D. J., F. Sigmundsson, and P. T. Delaney (2000), Comment on "Volume of magma accumulation or withdrawal estimated from surface uplift or subsidence, with application to the 1960 collapse of Kilauea volcano" by P. T. Delaney and D. F. McTigue, Bull. Volcanol., 61, 491-493.

Johnston, M. J. S., D. P. Hill, A. T. Linde, J. Langbein, and R. Bilham (1995), Transient deformation during triggered 
seismicity from the 28 June $M_{w}=7.3$ Landers earthquake at Long-Valley caldera, California, Bull. Seismol. Soc. Am., 85, 787-795.

Jónsson, S. (2002), Modeling volcano and earthquake deformation from satellite radar interferometric observations, Ph.D. thesis, Stanford Univ., Stanford, Calif.

Kussmaul, S., P. K. Hormann, E. Ploskonka, and T. Subieta (1977), Volcanism and structure of southwestern Bolivia, J. Volcanol. Geotherm. Res., 2, 73-111.

Lazo, M., R. Kosaka, A. Minaya, E. Gonzales, and J. Soto (1991), Evaluatión de la actividad sísmica del Volcán Sabancaya, in Volumen de resumenes extendidos del VII Congreso Peruano de Geología, pp. 19-22, Sociedad Geol. del Peru, Lima.

Leidig, M., and G. Zandt (2003), Modeling of highly anisotropic crust and application to the Altiplano-Puna volcanic complex of the central Andes, J. Geophys. Res., 108(B1), 2014, doi:10.1029/2001JB000649.

Lohman, R. B., M. Simons, and B. Savage (2002), Location and mechanism of the Little Skull Mountain earthquake as constrained by satellite radar interferometry and seismic waveform modeling, J. Geophys. Res., 107(B6), 2118, doi:10.1029/2001JB000627.

Lowry, A. R., M. W. Hamburger, C. M. Meertens, and E. G. Ramos (2001), GPS monitoring of crustal deformation at Taal Volcano, Philippines, J. Volcanol. Geotherm. Res., 105, 35-47.

Lu, Z., R. Fatland, M. Wyss, S. Li, J. Eichelberger, K. Dean, and J. Freymueller (1997), Deformation of New Trident volcano measured by ERS-1 SAR interferometry, Katmai National Park, Alaska, Geophys. Res. Lett., 24, 695-698.

Lu, Z., J. C. Wicks, D. Dzurisin, W. Thatcher, J. T. Freymueller, S. R. McNutt, and D. Mann (2000a), Aseismic inflation of Westdahl volcano, Alaska, revealed by satellite radar interferometry, Geophys. Res. Lett., 27, 1567-1570.

Lu, Z., J. C. Wicks, J. Power, and D. Dzurisin (2000b), Deformation of Akutan volcano, Alaska, revealed by satellite radar interferometry, J. Geophys. Res., 105, 21,483-21,496.

Lu, Z., D. Mann, J. Freymueller, and D. Meyer (2000c), Synthetic aperture radar interferometry of Okmok volcano, Alaska: Radar observations, J. Geophys. Res., 105, 10,791-10,806.

Lu, Z., J. C. Wicks, D. Dzurisin, W. Thatcher, and J. Power (2000d), Studies of volcanoes of Alaska by satellite radar interferometry, in Proceedings of the ERS-ENVISAT Symposium, Gothenburg, Sweden [CD-ROM], Eur. Space Agency, Spec. Publ. SP-461.

Lu, Z., J. C. Wicks, D. Dzurisin, J. A. Power, S. C. Moran, and W. Thatcher (2002a), Magmatic inflation at a dormant stratovolcano: 1996-1998 activity at Mount Peulik volcano, Alaska, revealed by satellite radar interferometry, J. Geophys. Res., 107(B7), 2134, doi:10.1029/2001JB000471.

Lu, Z., T. Masterlark, J. Power, D. Dzurisin, and J. C. Wicks (2002b), Subsidence at Kiska Volcano, western Aleutians, detected by satellite radar interferometry, Geophys. Res. Lett., 29(18), 1855, doi:10.1029/2002GL014948.

Lu, Z., J. A. Power, V. S. McConnell, J. C. Wicks, and D. Dzurisin (2002c), Preeruptive inflation and surface inter- ferometric coherence characteristics revealed by satellite radar interferometry at Makushin Volcano, Alaska: 19932000, J. Geophys. Res., 107(B11), 2266, doi:10.1029/ 2001JB000970.

Lu, Z., J. C. Wicks, D. Dzurisin, J. Power, W. Thatcher, and T. Masterlark (2003a), Interferometric synthetic aperture radar studies of Alaska volcanoes, Earth Obser. Mag., $12,8-18$.

Lu, Z., T. Masterlark, D. Dzurisin, R. Rykhus, and J. C. Wicks (2003b), Magma supply dynamics at Westdahl volcano, Alaska, modeled from satellite radar interferometry, J. Geophys. Res., 108(B7), 2354, doi:10.1029/2002JB002311.

Lundgren, P., S. Usai, E. Sansosti, R. Lanari, M. Tesauro, G. Fornaro, and P. Berardino (2001), Modeling surface deformation observed with synthetic aperture radar interferometry at Campi Flegrei caldera, J. Geophys. Res., 106(B9), 19,355-19,366.

Mann, D., and J. T. Freymueller (2003), Volcanic and tectonic deformation on Unimak Island in the Aleutian Arc, Alaska, J. Geophys. Res., 108(B2), 2108, doi:10.1029/ 2002JB001925.

Mann, D., J. Freymueller, and Z. Lu (2002), Deformation associated with the 1997 eruption of Okmok volcano, Alaska, J. Geophys. Res., 107(B4), 2072, doi:10.1029/ 2001JB000163.

Marsh, B. D. (1989), Magma chambers, Ann. Rev. Earth Planet. Sci., 17, 437-474.

Marsh, B. D., and M. Maxey (1985), On the distribution and separation of crystals in convecting magma, J. Volc. Geotherm. Res., 24, 95-150.

Massonnet, D., and K. Feigl (1998), Radar interferometry and its application to changes in the Earth's surface, Rev. Geophys., 36, 441-500.

Massonnet, D., M. Rossi, C. Carmona, F. Adragna, G. Peltzer, K. Feigl, and T. Rabaute (1993), The displacement field of the Landers earthquake mapped by radar interferometry, Nature, 364, 138-142.

Matthews, S. J., A. P. Jones, and M. C. Gardeweg (1994), Lascar volcano, northern Chile - Evidence for steady-state disequilibrium, J. Petrol., 35, 401-432.

Matthews, S. J., R. A. Marquillas, A. J. Kemp, F. K. Grange, and M. C. Gardeweg (1996), Active skarn formation beneath Lascar volcano, northern Chile: A petrographic and geochemical study of xenoliths in eruption products, J. Meterol. Geol., 14, 509-530.

Matthews, S. J., M. C. Gardeweg, and R. S. J. Sparks (1997), The 1984 to 1996 cyclic activity of Lascar Volcano, northern Chile: Cycles of dome growth, dome subsidence, and explosive eruptions, Bull. Volcanol., 59, 77-82.

Matthews, S. J., R. S. J. Sparks, and M. C. Gardeweg (1999), Piedras Grandes-Soncor eruptions, Lascar volcano, Chile; Evolution of zoned magma chamber in the central Andean upper crust, J. Petrol., 40, 1891-1919.

McTigue, D. F. (1987), Elastic stress and deformation near a finite spherical magma body: Resolution of the point source paradox, J. Geophys. Res., 92, 12,931-12,940.

Miller, T. P., R. G. McGimsey, D. H. Richter, J. R. Riehle, C. J. Nye, M. E. Yount, and J. A. Dumoulin (1998), Catalog of the 
historically active volcanoes of Alaska, U. S. Geol. Surv. Open File, 98-582104 pp.

Montgomery, D. R., G. Balco, and S. D. Willett (2001), Climate, tectonics, and the morphology of the Andes, Geology, 29, 579-582.

Muller, J. R., G. Ito, and S. J. Martel (2001), Effects of volcano loading on dike propagation in an elastic half-space, J. Geophys. Res., 106, 11,101-11,113.

Myers, S., S. Beck, G. Zandt, and T. Wallace (1998), Lithospheric-scale structure across the Bolivian Andes from tomographic images of velocity and attenuation for $\mathrm{P}$ and $\mathrm{S}$ waves, J. Geophys. Res., 103, 21,233-21,252.

Naranjo, J. A. (1985), Sulphur flows at Lastarria volcano in the north Chilean Andes, Nature, 313, 778-780.

Naranjo, J. A., and P. Francis (1987), High velocity debris avalanche at Lastarria volcano in the north Chilean Andes, Bull. Volcanol., 49, 509-514.

Newhall, C. G., and D. Dzurisin (1988), Historical unrest at large calderas of the world, U. S. Geol. Surv., 1855, 1108 pp.

Nishimura, T., S. Fujiwara, M. Murakami, M. Tobita, H. Nakagawa, T. Sagiya, and T. Tada (2001), The M6.1 earthquake triggered by volcanic inflation of Iwate volcano, northern Japan, observed by satellite radar interferometry, Geophys. Res. Lett., 28, 635-638.

Oppenheimer, C., P. W. Francis, D. A. Rothery, and R. W. T. Carlton (1993), Infrared image analysis of volcanic thermal features: Lascar Volcano, Chile 1984-1992, J. Geophys. Res., 98, 4269-4286.

Price, E. J. (2002), Elements of the active magmatic system of Seguam Island, Aleutian Islands, Alaska inferred from co and post-eruptive surface deformation spanning $1993-$ 2000, Eos Trans. AGU, 83(47), Fall Meet. Suppl., Abstract T21D-07.

Pritchard, M. E. (2003), Recent crustal deformation in westcentral South America, Ph.D. thesis, Calif. Inst. Technol., Pasadena. (Available at http://etd.caltech.edu/etd/available/ etd-06022003-105512/)

Pritchard, M. E., and M. Simons (2002), A satellite geodetic survey of large-scale deformation of volcanic centres in the central Andes, Nature, 418, 167-171.

Pritchard, M. E., M. Simons, P. Rosen, S. Hensley, and F. Webb (2002), Co-seismic slip from the 1995 July 30 $M_{w}=8.1$ Antofagasta, Chile, earthquake as constrained by InSAR and GPS observations, Geophys. J. Int., 150, 362-376.

Puglisi, G., and M. Coltelli (2001), SAR interferometry applications on active volcanoes: State of the art and perspectives for volcano monitoring, Il Nuovo Cimento, 24, 133-145.

Pyle, D. M. (1995), Mass and energy budgets of explosive volcanic eruptions, Geophys. Res. Lett., 22, 563-566.

Riller, U., I. Petrinovic, J. Ramelow, M. Strecker, and O. Oncken (2001), Late Cenozoic tectonism, collapse caldera and plateau formation in the central Andes, Earth Planet. Sci. Lett., 188, 299-311.

Rosen, P. A., S. Hensley, H. A. Zebker, F. H. Webb, and E. J. Fielding (1996), Surface deformation and coherence measurements of Kilauea Volcano, Hawaii, from SIR-C radar interferometry, J. Geophys. Res., 101, 23,109-23,125.
Rosen, P. A., S. Hensley, I. R. Joughin, F. K. Li, S. N. Madsen, E. Rodríguez, and R. M. Goldstein (2000), Synthetic Aperture Radar Interferometry, Proceedings of the IEEE, 88 , $333-382$.

Rymer, H., J. B. Murray, G. C. Brown, F. Ferrucci, and W. J. McGuire (1993), Mechanisms of magma eruption and emplacement at Mt. Etna between 1989 and 1992, Nature, 361, 439-441.

Sambridge, M. (1998), Exploring multi-dimensional landscapes without a map, Inverse Problems, 14, 427-440.

Sambridge, M. (1999a), Geophysical inversion with a neighbourhood algorithm: I. Searching a parameter space, Geophys. J. Int., 138, 479-494.

Sambridge, M. (1999b), Geophysical inversion with a neighbourhood algorithm: II. Appraising the ensemble, Geophys. J. Int., 138, 727-746.

Sambridge, M. (2001), Finding acceptable models in nonlinear inverse problems using a neighbourhood algorithm, Inverse Problems, 17, 387-403.

Sambridge, M. S., and B. L. N. Kennett (2001), A novel method of hypocentre location, Pure Appl. Geophys., 158, 241-257.

Scharroo, R., P. N. A. M. Visser, and G. J. Mets (1998), Precise orbit determination and gravity field improvement for the ERS satellites, J. Geophys. Res., 103, 8113-8127.

Schilling, F. R., G. M. Partzch, H. Brasse, and G. Schwarz (1997), Partial melting below the magmatic arc in the central Andes deduced from geoelectromagnetic field experiments and laboratory data, Phys. Earth Planet. Inter., 103, 17-31.

Schmitz, M., W.-D. Heinsohn, and F. R. Schilling (1997), Seismic, gravity and petrological evidence for partial melt beneath the thickened central Andean crust $\left(21-23^{\circ} \mathrm{S}\right)$, Tectonophysics, 205, 127-140.

Sigmundsson, F., P. Durand, and D. Massonnet (1999), Opening of an eruptive fissure and seaward displacement at Piton de la Fournaise volcano measured by RADARSAT satellite radar interferometry, Geophys. Res. Lett., 26, 533-536.

Simkin, T., and L. Siebert (1994), Volcanoes of the world, Geoscience Press, Tucson, Ariz.

Simons, M., Y. Fialko, and L. Rivera (2002), Coseimic deformation from the $1999 M_{w} 7.1$ Hector Mine, California, earthquake as inferred from InSAR and GPS observations, Bull. Seismol. Soc. Am., 92, 1390-1402.

Smithsonian Institution (1988), Sabancaya, Sci. Event Alert Net, 13.

Smithsonian Institution (1990a), Sabancaya, Bull. Global Volcanism Network, 15(5).

Smithsonian Institution (1990b), Sabancaya, Bull. Global Volcanism Network, 15(6).

Smithsonian Institution (1990c), Sabancaya, Bull. Global Volcanism Network, 15(7).

Smithsonian Institution (1991a), Sabancaya, Bull. Global Volcanism Network, 16(5).

Smithsonian Institution (1991b), Sabancaya, Bull. Global Volcanism Network, 16(7).

Smithsonian Institution (1993a), Aracar, Bull. Global Volcanism Network, 18(4). 
Smithsonian Institution (1993b), Lascar, Bull. Global Volcanism Network, 18(4).

Smithsonian Institution (1993c), Lascar, Bull. Global Volcanism Network, 18(11).

Smithsonian Institution (1993d), Nevados Ojos del Salado, Bull. Global Volcanism Network, 18(11).

Smithsonian Institution (1994a), Sabancaya, Bull. Global Volcanism Network, 19(3).

Smithsonian Institution (1994b), Lascar, Bull. Global Volcanism Network, 19(1).

Smithsonian Institution (1994c), Lascar, Bull. Global Volcanism Network, 19(3).

Smithsonian Institution (1995), Sabancaya, Bull. Global Volcanism Network, 20(5).

Smithsonian Institution (1996a), Ubinas, Bull. Global Volcanism Network, 21(7).

Smithsonian Institution (1996b), Guallatiri, Bull. Global Volcanism Network, 21(7).

Smithsonian Institution (1997a), Sabancaya, Bull. Global Volcanism Network, 22(7).

Smithsonian Institution (1997b), Irruputuncu, Bull. Global Volcanism Network, 22(1).

Smithsonian Institution (1998a), Sabancaya, Bull. Global Volcanism Network, 23(5).

Smithsonian Institution (1998b), Sabancaya, Bull. Global Volcanism Network, 23(8).

Smithsonian Institution (1998c), Sabancaya, Bull. Global Volcanism Network, 23(10).

Smithsonian Institution (2000a), Sabancaya, Bull. Global Volcanism Network, 25(5).

Smithsonian Institution (2000b), Lascar, Bull. Global Volcanism Network, 25(6).

Smithsonian Institution (2003), Uturuncu, Bull. Global Volcanism Network, 8(6).

Sparks, R. S. J., M. C. Gardeweg, E. S. Calder, and S. J. Matthews (1997), Erosion by pyroclastic flows on Lascar Volcano, Chile, Bull. Volcanol., 58, 557-565.

Tada, T., and M. Hashimoto (1989), Recent crustal deformation around the Aira caldera, Kagoshima, Japan, and its relation to the volcanism of Sakurajima volcano, paper presented Kagoshima International Conference on Volcanoes, Natl. Inst. for Res. Adv., Tokyo.

Thouret, J.-C., A. Gourgaud, M. Uribe, A. Rodriguez, R. Guillande, and G. Salas (1995), Geomorphological and geological survey, and SPOT remote sensing of the current activity of Nevado Sabancaya stratovolcano (south Peru): Assessment for hazard-zone mapping, Zeitschrift Geomorph. N. F., 39, 515-535.

Thouret, J.-C., E. Juvigne, A. Gourgaud, P. Boivin, and J. Davila (2002), Reconstruction of the AD 1600 Huaynaputina eruption based on the correlation of geologic evidence with early Spanish chronicles, J. Volcanol. Geotherm. Res., $115,529-570$.

Toksöz, M. N., and S. C. Solomon (1973), Thermal history and evolution of the moon, The Moon, 7, 251-278.

Voight, B., et al. (1999), Magma flow instability and cyclic activity at Soufriere Hills volcano, Montserrat, British West Indies, Nature, 283, 1138-1142.
Watanabe, H., S. Okubo, S. Sakashita, and T. Maekawa (1998), Drain-back process of basaltic magma in the summit conduit detected by microgravity observation at IzuOshima volcano, Japan, Geophys. Res. Lett., 25, 28652868.

Wessel, P., and W. H. F. Smith (1998), New, improved version of Generic Mapping Tools released, Eos Trans. AGU, 79, 579.

Wicks, C., Jr., W. Thatcher, and D. Dzurisin (1998), Migration of fluids beneath Yellowstone caldera inferred from satellite radar interferometry, Science, 282, 458-462.

Wicks, C. W., D. Dzurisin, S. Ingebritsen, W. Thatcher, Z. Lu, and J. Iverson (2002), Magmatic activity beneath the quiescent Three Sisters volcanic center, central Oregon Cascade Range, USA, Geophys. Res. Lett., 29(7), 1122, doi:10.1029/ 2001 GL014205.

Wigger, P. J., M. Schmitz, M. Araneda, G. Asch, S. Baldzuhn, P. Giese, W.-D. Heinsohn. E. Martínez, E. Ricaldi. P. Röwler, and J. Viramonte (1994), Variation in crustal structure of the southern central Andes deduced from seismic refraction investigations, in Tectonics of the Southern Central Andes: Structure and Evolution of an Active Continental Margin, edited by K.-J. Reutter, E. Scheuber, and P. J. Wigger, pp. 23-48, Springer-Verlag, New York.

Williams, C. A., and G. Wadge (1998), The effects of topography on magma chamber deformation models: Application to Mt. Etna and radar interferometry, Geophys. Res. Lett., 25, $1549-1552$.

Williams, C. A., and G. Wadge (2000), An accurate and efficient method for including the effects of topography in three-dimensional elastic models of ground deformation with applications to radar interferometry, J. Geophys. Res., 105, 8103-8120.

Wooster, M. J. (2001), Long-term infrared surveillance of Lascar Volcano: Contrasting activity cycles and cooling pyroclastics, Geophys. Res. Lett., 28, 847-850.

Wooster, M. J., and D. A. Rothery (1997), Thermal monitoring of Lascar Volcano, Chile, using infrared data from the alongtrack scanning radiometer: A 1992-1995 time series, Bull. Volcanol., 58, 566-579.

Wörner, G., K. Hammerschmidt, F. Henjes-Kunst, J. Lezaun, and H. Wilke (2000), Geochronology $\left({ }^{40} \mathrm{Ar} /{ }^{39} \mathrm{Ar}, \mathrm{K}-\mathrm{Ar}\right.$ and He-exposure ages) of Cenozoic magmatic rocks from Northern Chile $\left(18-22^{\circ} \mathrm{S}\right)$ : Implications for magmatism and tectonic evolution of the central Andes, Rev. Geol. Chile, 27, $205-240$

Yang, X.-M., P. M. Davis, and J. H. Dieterich (1988), Deformation from inflation of a dipping finite prolate spheroid in an elastic half-space as a model for volcanic stressing, J. Geophys. Res., 93, 4249-4257.

Yuan, X., et al. (2000), Subduction and collision processes in the Central Andes constrained by converted seismic phases, Nature, 408, 958-961.

Zandt, G., M. Leidig, J. Chmielowski, D. Baumont, and X. Yuan (2003), Seismic detection and characterization of the Altiplano-Puna magma body, central Andes, Pure Appl. Geophys., 160, 789-807.

Zebker, H. A., P. A. Rosen, R. M. Goldstein, A. Gabriel, and C. L. Werner (1994), On the derivation of coseismic displace- 
ment-fields using differential radar interferometry: The Landers earthquake, J. Geophys. Res., 99, 19,617-19,634. Zebker, H. A., P. A. Rosen, and S. Hensley (1997), Atmospheric effects in interferometric synthetic aperture radar surface deformation and topographic maps, J. Geophys. Res., $102,7547-7563$.
Zebker, H. A., F. Amelung, and S. Jonsson (2000), Remote sensing of volcano surface and internal processes using radar interferometry, in Remote Sensing of Active Volcanism, Geophys. Monogr. Ser., vol. 116, edited by P. J. Mouginis-Mark, J. A. Crisp, and J. H. Fink, pp. 179-205, AGU, Washington D.C. 